\title{
Hans-Jürgen Bömelburg
}

\section{Polen und die deutsche Nation - Konfligierende Identitätszuschreibungen und antagonistische Entwürfe politischer Ordnung}

Das Alte Reich und Polen-Litauen bildeten durch die frühe Neuzeit zwei annähernd gleich große Reichsgefüge, die ganz Zentraleuropa prägten. Infolge einer in beiden Reichsverbänden nur für die Defensive geeigneten Militärverfassung und einer fehlenden politischen Verdichtung mit mehrfachen Loyalitäten an der deutschen Ost- wie an der polnischen Westgrenze ist die deutsch-polnische Grenze in der bellizistischen frühen Neuzeit die wohl friedlichste Grenze innerhalb Europas überhaupt und veränderte sich über drei Jahrhunderte bis zur Ersten Teilung Polen-Litauens (1772) nicht ${ }^{1}$. Neben dieser stabilen politischen Koexistenz entwikkelten sich jedoch in beiden Reichsverbänden konfligierende Nations- und Identitätszuschreibungen, die aus der Dynamik nationaler Diskurse in zunehmend patriotisch besetzten Öffentlichkeiten erwuchsen und dieselben autogenen Geschichtsräume mehrfach beanspruchten, die jeweils andere Vorgeschichte mit eigenen Heroen besetzten und historische Abhängigkeiten konstruierten. Da humanistische Konzepte eine starke rhetorische Durcharbeitung forderten und der gelehrte Habitus einen Wettkampf der Leistungen beförderte, folgte eine kommunikative Aufladung in Richtung einer konkurrierenden Nationalisierung2.

Solche Konzepte erreichten die deutschen Eliten ca. eine Generation früher (um 1490) als ihre polnischen Nachbarn (um 1515). Diese zeitliche Verzögerung und die entwickelteren Druckmedien und Öffentlichkeiten im Reich führten dazu, daß sich der deutsch-polnische „nationale Wettkampf“ entlang eines Schemas von deutscher Aktion und polnischer Reaktion entwickelte, das sich durch

1 Hans-Jürgen Bömelburg, Die Tradition einer multinationalen Reichsgeschichte in Mitteleuropa - Historiographische Konzepte gegenüber Altem Reich und Polen-Litauen sowie komparatistische Perspektiven, in: ZfO 53 (2004) 318-350; zu den Strukturen an der Grenze: Hans-Jürgen Bömelburg, Grenzgesellschaft und mehrfache Loyalitäten. Die brandenburgisch-preußisch-polnische Grenze 1656-1772, in: ZfO 55 (2006) 56-78.

2 Bisher dargestellt insbesondere am italienisch-deutschen Beispiel: Herfried Münkler, Hans Grünberger, Kathrin Meyer, Nationenbildung. Die Nationalisierung Europas im Diskurs humanistischer Intellektueller. Italien und Deutschland (Politische Ideen 8, Berlin 1998); Caspar Hirschi, Wettkampf der Nationen. Konstruktionen einer deutschen Ehrgemeinschaft an der Wende vom Mittelalter zur Neuzeit (Göttingen 2005). 
das 16. und 17. Jahrhundert fortpflanzte. Thesenhaft sei formuliert: Das Konstrukt „Deutsche“ und „deutsche Nation“ wurde hierbei zu dem Bezugspunkt polnischer Identitätszuschreibungen der frühen Neuzeit und mündete schließlich auch in die nationale Verortung von politischen Ordnungsvorstellungen. Während den Deutschen ein Streben nach „tyrannischer" absoluter Herrschaft eigen sei, zeichne die Polen das Streben nach "milder Herrschaft" und einer Bewahrung der „polnischen Freiheiten“ aus - so die polnische Wahrnehmung auf der Basis der als „deutsch“ aufgefaßten habsburgischen Politik in Ostmitteleuropa zwischen 1547 (Niederwerfung der böhmischen Ständeopposition) und der Durchsetzung eines bürokratischen Zentralismus in Böhmen und Ungarn im 17. und 18. Jahrhundert. Eine „teutsche Libertät“ existiert in frühneuzeitlichen polnischen Deutungsmustern nicht.

Der reaktive, kritische und vielfach ablehnende Bezug auf tatsächliche oder angebliche Prätensionen und Ansprüche „deutscher Herren“ ist so eine Konstante frühneuzeitlicher polnischer Ordnungsvorstellungen. Dies soll im folgenden anhand von 1. konkurrierenden humanistischen Diskursen, 2. der Publizistik von drei zeitlich eng beieinander liegender Interregna $(1572,1575,1586 / 87)$, 3. den Ordnungsvorstellungen im Umfeld des polnischen Wasahofes zwischen 1587 und 1668 sowie 4. den Debatten zwischen polnischen und deutschen Rechtshistorikern im letzten Drittel des 17. und im 18. Jahrhundert analysiert werden. Die Reichweite solcher Argumentationen muß medien- und textabhängig differenziert beurteilt werden, wobei jeweils auch eine skizzenhafte Analyse der Reichweite geboten wird. Berücksichtigt wird schließlich auch die Rolle preußischer und schlesischer Identitätszuschreibungen - Regionen, die frühneuzeitlich von polnischen wie deutschen Ordnungsvorstellungen beansprucht wurden.

\section{Konkurrierende nationalgeschichtliche Entwürfe von deutschen und polnischen Humanisten}

Das deutsche humanistische Nationskonstrukt, das seine Motivation aus einer Konkurrenz zu den Thesen italienischer Humanisten bezog, entstand zu einem erheblichen Teil in der deutsch-polnischen Kontaktzone in Krakau. In Krakau, der um 1500 bedeutendsten Universität Mitteleuropas, hielten sich zwischen 1490 und 1520 mehrere führende deutsche Humanisten auf, unter anderem Konrad Celtis zwischen 1489 und 1491, Heinrich Bebel 1492-149432, Johannes Aventinus

3 Zu dessen Geschichtsschreibung: Dieter Mertens, „Bebelius ... patriam Sueviam ... restituit“. Der poeta laureatus zwischen Reich und Territorium, in: Zeitschrift für Württembergische Landesgeschichte 42 (1983) 145-173; Klaus Graf, Heinrich Bebel (1472-1518). Wider ein barbarisches Latein, in: Humanismus im deutschen Südwesten. Biographische Profile, hrsg. v. Paul Gerhard Schmidt (Sigmaringen 1993) 179-194. Bebels Werke wurden im 16. Jahrhundert auch in Krakau gelesen, so befanden sich dessen „Facetiae“ in der Decius'schen Bibliothek, vgl. Wtodzimierz Budka, Biblioteka Decjuszów [Die Bibiothek der Fami- 
1501/024, Caspar Ursinus Velius 1505-15075, Johannes Hadelius 1515/166 und Joachim Vadian 1517 und 1519. Dabei kam es an der Universität und in der bürgerlichen städtischen Soziabilität zu Kontakten zwischen deutschen und polnischen Humanisten ${ }^{7}$.

Die Entwürfe einer „Germania magna“ aus der Feder deutscher Humanisten und einer „Sarmatia magna“, einer polnischen Nationalgeschichte, kollidierten in mehreren Bereichen, so der geographischen Reichweite beider Nationen, der germanischen und polnischen Frühgeschichte und dem Verhältnis zwischen beiden Reichsverbänden. Beispielhaft kann dies an Celtis demonstriert werden, dessen Kontakte mit den polnischen Eliten belegt sind, der sich im Unterschied zu anderen Humanisten in Krakau als reifer Mann aufhielt, ein umfangreiches Textcorpus hinterließ und in seinen Gedichten Krakau als eine „sarmatische Stadt“ bezeich-

lie Decius'], in: Silva rerum 4 (1928) 110-126, hier 120. Andere Werke Bebels tauchen in Krakauer Nachlaßinventaren auf, vgl. Artur Benis, Materyały do historyi drukarstwa i księgarstwa w Polsce [Materialien zur Geschichte des Druck- und Buchwesens in Polen], in: Archiwum do dziejów literatury i oświaty w Polsce 7 (1892) 1-71, 202-240, hier 222.

4 Aventinus erwähnt in seiner „Bayerischen Chronik“ bei der Einführung der durchgängig negativ charakterisierten Jagiellonen auch seinen Aufenthalt in Krakau: „dabei erwarb er [Kazimierz IV., H.-J. B.] drei Sün, so nacheinander in Poln regiert haben: künig Albrecht, künig Alexander und künig Sigmund, so ich all drei mitsambt irer mueter (so ein schlecht geistlich diemütig leben füeret) zu Cracau in der hauptstadt Poln gesehen hab“. Johannes Turmair's genannt Aventinus, Sämmtliche Werke, hrsg. v. der Kgl. Akademie der Wissenschaften, 6 Bde. (München 1881-1908) Bd. 5 522. Die Charakteristik der polnischen Herrscher und der Jagiellonen, die Aventinus als vom Reich abhängig und „schlechte Christen“ darstellt, denen er politischen Erfolg allerdings nicht absprechen kann, mündet ebenda in die ratlose Feststellung: „Also get's und niemand verstet's.“ Insgesamt ist nicht erkennbar, daß der Aufenthalt in Krakau dem Autor Kenntnisse der polnischen Geschichte vermittelt hätte. Vgl. auch Alois Schmid, Die historische Methode des Johannes Aventinus, in: Blätter für deutsche Landesgeschichte 113 (1977) 338-395.

5 Gustav Bauch, Caspar Ursinus Velius der Hofhistoriograph Ferdinands I. und Erzieher Maximilians II. (Budapest 1886).

6 Hermann Wiegand, Johannes Hadeke-Hadelius. Ein niedersächsischer Wanderhumanist in Rostock, Krakau und Wien, in: Humanismus im Norden. Frühneuzeitliche Rezeption antiker Kultur und Literatur an Nord- und Ostsee, hrsg. v. Thomas Haye (Chloe 32, Amsterdam 2000) 105-134.

7 Vergleichend zur Rolle Krakaus: Krakau, Prag und Wien. Funktionen von Metropolen im frühmodernen Staat, hrsg. v. Marina Dmitrieva, Karen Lambrecht (Stuttgart 2000); zu Kontakten zwischen deutschen und polnischen Humanisten: Hans-Jürgen Bömelburg, Frühneuzeitliche Nationen im östlichen Europa. Das polnische Geschichtsdenken und die Reichweite einer humanistischen Nationalgeschichte (1500-1700) (Veröffentlichungen des Nordost-Instituts 4, Wiesbaden 2006) 57-73; im folgenden zitiert: Bömelburg, Frühneuzeitliche Nationen. Tadeusz Ulewicz, Literarische Kreise und „Gesellschaften“ in Krakau und Kleinpolen im Zeitalter der Renaissance, in: Der polnische Humanismus und die europäischen Sodalitäten. Akten des polnisch-deutschen Symposions vom 15.-19. Mai 1996 in Krakau, hrsg. v. Stephan Füssel, Jan Pirożyński (Pirckheimer Jahrbuch für Renaissance- und Humanismusforschung 12, Wiesbaden 1997) 39-72. In manchen Details weiter heranzuziehen: Gustav Bauch, Deutsche Scholaren in Krakau in der Zeit der Renaissance 1460 bis 1520 (Breslau 1901). 
nete ${ }^{8}$. Zugleich ist jedoch in diesen Gedichten für die Region an der Weichsel stets eine Berufung auf die als ruhmeswürdig empfundene germanisch-deutsche Frühzeit der Region erkennbar. Hier wirkte die Rezeption antiker geographischer Vorstellungen (Ptolemäus) weiter, wonach die Regionen westlich der Weichsel als Teil der Germania aufgefaßt wurden?.

Selbst in Celtis Beschreibung des östlich der Weichsel liegenden Preußens wurde dessen Bevölkerung als ein deutscher Stamm angesprochen, der nun aber treulos einem „sarmatischen Tyrannen“ diene und seinen "deutschen Herrn“ grundlos hasse ${ }^{10}$. Das Land sei jedoch durch zivilisatorische Errungenschaften und die germanische Frühzeit (Landnahme der Goten) deutsch geprägt. Die Kriege zwischen dem Deutschen Orden und Polen-Litauen beschrieb Celtis schließlich als deutsch-polnische Auseinandersetzungen, in dem die „Feinde“ nach unglücklichem Verlauf den Sieg errungen hätten ${ }^{11}$.

Mit diesem „kalten“ Blick auf die polnische Geschichte, die in erster Linie als eine gegnerische wahrgenommen wurde, stand Celtis nicht allein. Ähnlich dachten deutschsprachige Humanisten wie Erasmus Stella oder Eobanus Hessus, die sich im Preußenland aufhielten, in Diensten der Ordensdiplomatie standen (Stella

8 Stefan Zabtocki, Beschreibungen des Ostens in den Elegien von Konrad Celtis, in: Landesbeschreibungen Mitteleuropas vom 15. bis 17. Jahrhundert, hrsg. v. Hans-Bernd Harder (Köln, Wien 1983) 141-163. Zu Celtis und dessen Aufenthalt in Krakau liegen in polnischer Sprache zahlreiche Beiträge vor, die aber über die Krakauer Zeit nicht hinausgehen, vgl. Karol Mecherzyński, O pobycie w Polsce Konrada Celtesa i jego wpływie na rozbudzenie humanizmu [Über den Aufenthalt von Konrad Celtis in Polen und dessen Einfluß auf die Ausbreitung des Humanismus], in: Rozprawy i sprawozdania Wydziału Filologicznego Akademie Umiętności, 4 (1876) 1-51; Antonina Jelicz, Konrad Celtis na tle wczesnego renesansu w Polsce [Konrad Celtis vor dem Hintergrund der Frührenaissance in Polen] (Warszawa 1956); Wtadystaw Pociecha, Królowa Bona. Czasy i ludzie odrodzenia [Königin Bona. Zeiten und Menschen der Renaissance], 4 Bde., Bd. 2 (Poznań 1949-1958) 6 (mit weiterer Literatur). Das Celtisbild ist in der polnischen Forschung negativ, da dieser seit dem 19. Jahrhundert als Verkünder der Überlegenheit deutscher Kultur rezipiert wird. Die deutsche Celtis-Forschung rezipiert die polnischsprachigen Arbeiten durchweg nicht.

9 Überblick über die kartographische Darstellung der Germania: Burghart Schmidt, Mappae Germaniae. Das Alte Reich in der kartographischen Überlieferung der Frühen Neuzeit, in: Imperium Romanum - Irregulare Corpus - Teutscher Reichs-Staat. Das Alte Reich im Verständnis der Zeitgenossen und der Historiographie, hrsg. v. Matthias Schnettger (Veröffentlichungen des Instituts für Europäische Geschichte Mainz, Beiheft 57, Mainz 2002) 3-25. Zur Krakauer Ptolemäus-Rezeption: Jadwiga Bzinkowska, Od Sarmacji do Polonii. Studia nad początkami obrazu kartograficznego Polski [Von Sarmatien nach Polen. Studien über die Anfänge des kartographischen Bilds von Polen] (Kraków 1994); erhaltene Handschriften: Bożena Modelska-Strzelecka, Le manuscrit cracovien de la „Geografie“ de Ptolémée (Varsovie 1960).

10 „Hinc propior codano Prussiae tendis ad vrbes / Vistula: teutonicae littora gentis habens / Quae nunc sarmatico seruit malefida tyranno / Germanum dominum forte perosa suum (...).“ Moderne Edition, in: Humanistische Lyrik des 16. Jahrhunderts. Lateinisch und deutsch, hrsg. v. Wilhelm Kühlmann (u.a.) (Bibliothek der frühen Neuzeit 1,5, Frankfurt a. M. 1997) 96-99.

11 „Sed quondam Gedonum, gothorum a nomine dictum / Hincque sinus codanus nomina clarus habet. / Ad cuius tractum: bellum memorabile gestum est / Inter teutonicos polonicosque viros / Heu, pudet: aduerso parta est victoria marte“. Ebenda 98. 
im Dienste des vorletzten Hochmeisters in Preußen Friedrich von Sachsen, Hessus am Riesenburger Hofe des Bischofs von Pomesanien Hiob von Dobeneck) und mit polnischen Humanisten wie Johannes Dantiscus und Andrzej Krzycki Kontakte unterhielten ${ }^{12}$.

1512 nahm Hessus am polnischen Reichstag in Piotrków teil und plädierte für eine Rückübertragung des westlichen Preußenlandes an den Orden ${ }^{13}$. Preußen, „ein Reich auf den sarmatischen Fluren“, sei vom Orden „mit deutschem Blut“ erkauft worden; eine Rückgabe werde dem polnischen König „Anerkennung und beispiellosen Ruhm bei der deutschen Nation“ sowie die Herrschaft im „sarmatischen Erdkreis“ sichern ${ }^{14}$. Ähnlich konstatierte Aventinus - wohl auf der Basis einer einseitigen Interpretation seiner Krakauer Gewährsleute und Erfahrungen die ganze ältere Geschichte des östlichen Europa sei von den Deutschen geprägt ${ }^{15}$.

Es können also zwei lebensweltliche und politische Kontaktzonen zwischen deutschen Humanisten und polnischen Eliten unterschieden werden, zunächst die Metropole Krakau mit ihrer Infrastruktur aus Universität, Domkapitel und königlichem Hof, sowie zweitens die politischen Kontakte zwischen den Eliten im diplomatischen und militärischen Konflikt zwischen Polen-Litauen und dem Deutschen Orden. Dabei waren auch in Diensten des polnischen Hofes muttersprachlich deutsche Humanisten tätig, wie der Danziger Diplomat Johannes Flachsbinder/Joannes Dantiscus/Jan Dantyszek ${ }^{16}$.

12 Wilhelm Kühlmann, Werner Straube, Zur Historie und Pragmatik humanistischer Lyrik im alten Preußen: Von Konrad Celtis über Eobanus Hessus zu Georg Sabinus, in: Kulturgeschichte Ostpreußens in der Frühen Neuzeit, hrsg. v. Klaus Garber (u. a.) (Frühe Neuzeit 56, Tübingen 2001) 657-736; im folgenden zitiert: Kühlmann, Straube, Zur Historie; Biographie: Carl Krause, Helius Eobanus Hessus. Sein Leben und seine Werke. Ein Beitrag zur Culturund Gelehrtengeschichte des 16. Jahrhunderts, 2 Bde. (Gotha 1879); zum Riesenburger Hof: Kurt Forstreuter, Vom Ordensstaat zum Fürstentum. Geistige und politische Wandlungen im Deutschordensstaate Preußen unter den Hochmeistern Friedrich und Albrecht (1498-1525) (Kitzingen 1951) 92-109.

13 Helius Eobanus Hessus, Ad Serenissimum Sigismundum Regem Poloniae pro Magistratibus militiae Teutonicorum Prussiae in conventu Petricoviensi. [11539]. Mit Anmerkungen ediert und übersetzt bei Küblmann, Straube, Zur Historie 693-702. Zum politischen Hintergrund und zum (2.) Sejm 1512 in Piotrków vgl. Volumina constitutionum. Bd. 1, hrsg. v. Stanistaw Grodzicki (u. a.) (Warszawa 1996) 254-265.

14 „Non aliqua tecum de novitate loquor / Quod sibi Sarmaticis Regnum fundarit in oris (...) sanguine Teutonico, sed postquam fortiter empta est / Exuit antiquos Prussia tota Deos / Romana Imperii Friderichus sceptra tenebat (...). Teutonicae accedet favor, \& nova gloria gentis, / Largiri imperium cui volet illa potest. (...) Sic tua continuis dilatans Regna triumphis, / Sarmatico populus solus in orbe regas.“, in: Küblmann, Straube, Zur Historie 693-696.

15 „So find ich, das in den landen, da iezo Winden Reussen Poln Tatarn wonen, vor zeiten Teutsch, nemlich Saxen Schwaben Hannen Gueten Baiern gewont haben, als ich dan auch gehört hab von Chunrad Celtis, Johansen Stabio (...). Die grossen hauptstedt noch heutigen tag, auch etich ganz gegent in Winden Polen Reussen Ungern sein noch teutsch, lassen niemant einkommen dan geporn Teutsch.“ Aventinus, Sämmtliche Werke, Bd. 4361.

16 Joannes Dantiscus (1485-1548). Polish Ambassador and Humanist. Proceedings of the internationale colloquium Brussels. 22.-23. Mai 1995, hrsg. v. Jozef Ijsewijn, Wouter Bracke (Studia Europaea 2, Brussels 1996); zum multikulturellen Lebensentwurf von Dantiscus: Jerzy Axer, Jan Dantyszek - dyplomata, mąż, ojciec, biskup warmiński: granicy (nie)lojal- 
Auch die deutschsprachigen Bevölkerungen bezogen keineswegs entlang sprachlicher und kultureller Grenzen Stellung: Die städtischen Eliten des Königlichen Preußens (Danzig, Elbing, Thorn) unterstützten aus wirtschaftlichen und politischen Gründen den polnischen Hof. Unter den deutschsprachigen Bürgern Danzigs fand die von Celtis und Hessus propagierte Integration in eine deutsche Nation im 16. Jahrhundert wenig Widerhall. Der Bürgerssohn Martin Gruneweg formulierte in seinen Lebenserinnerungen die Danziger Position: „Mitt dieser Polnischen Nation hat sich Dantzig so verbunden, gleich were sie mitt ihr eine Nation. Solches komt nirgendts anders heer nur aus altter liebe und freintschafft. Warlichen, es haben unsere Vorfahren nicht gewust besseren Schutzherren zufinden als den Polnischen König." 17

Auch in Krakau wurden die Konstruktionen zugereister deutscher Humanisten von der alteingesessenen deutschsprachigen Stadtbevölkerung nicht geteilt. $\mathrm{Ru}$ dolf Agricola der Jüngere ${ }^{18}$ berichtete in einem Brief an Joachim Vadian aus dem Jahre 1520 in abwertendem Ton über die zurückhaltende Einstellung des Krakauer Bürgertums, „polonisierte Deutsche“, denen man nicht trauen könne, die sich an den deutsch-polnischen Konflikten nicht beteiligten, sondern jeweils auf die Seite des „Siegers“ schlügen. Bei dem erwähnten Konflikt handelte es sich um den sog. „Reiterkrieg“ zwischen dem Deutschen Orden und Polen (1519/21), der von Agricola in seiner Korrespondenz in nationalen Dimensionen interpretiert $\operatorname{wird}^{19}$.

ności [Johannes Dantiscus - Diplomat, Ehemann, Vater und ermländischer Bischof: Grenzen der (Nicht)Loyalität], in: Panorama lojalności. Prusy Królewskie i Prusy Książęce w XVI wieku [Panorama der Loyalitäten. Das Königliche Preußen und das Herzogtum Preußen im 16. Jh.], (Eseje i studia 4, Warszawa 2001) 66-72; Biographie: Inge Brigitte Müller-Blessing, Johannes Dantiscus von Höfen. Ein Diplomat und Bischof zwischen Humanismus und Reformation (1485-1548), in: ZGAE 31/32 (1967/68) 59-238; Kontakte mit deutschen Humanisten: Franz Hipler, Beiträge zur Geschichte der Renaissance und des Humanismus aus dem Briefwechsel des Johannes Dantiscus, in: ZGAE 9 (1887-1890) 471-572; eine moderne Edition ist im Erscheinen: Corpus epistolarum Ioannis Dantisci, hrsg. v. Jerzy Axer, Bd. 1 (Warsaw, Cracow 2004).

17 Die Aufzeichnungen des Dominikaners Martin Gruneweg (1562-ca. 1618). Über seine Familie in Danzig, seine Handelsreisen in Osteuropa und sein Klosterleben in Polen, 4 Bde, hrsg. v. A. Bues (Wiesbaden 2008), Bd. 1, 288.

18 Agricola unterhielt Kontakte mit führenden polnischen Politikern wie Krzysztof Szydłowiecki (1467-1532), dem er sein Werk Hymnus de divo praesule et Martyre Stanislao, tutelari Poloniae Patrono (Cracoviae 1519) widmete. Vgl. Jerzy Kieszkowski, Kanclerz Krzysztof Szydłowiecki. Z dziejów kultury i sztuki Zygmuntowskich czasów [Kanzler Krzysztof Szydłowiecki. Aus der Kunst- und Kulturgeschichte zu Zeiten Zygmunts I.], 2 Bde., Bd. 2 (Poznań 1912) 324-326. Biographie: Gustav Bauch, Rudolphus Agricola Junior. Ein Beitrag zur Geschichte des Humanismus im deutsch-polnisch-ungarischen Osten (Breslau 1892).

19 „Id praeterea tibi indubitata fide persuadeas: adeo esse me tuum, ut esse magis tecum nequeam, adeoque Cracoviae invitum agere, ut ibidem diutius immorari molestissimum mihi sit. Non est Germanus, quin ipsi Judaeis omnibus postponantur; nulla fides toti Cracoviae et praesertim polonicatis Germanis, qui nos exteros nullo amore tenent; fortunam enim belli sequuntur. Si Germani victores evadunt, nobiscum gaudent; si Poloni, cum ipsis; interimque Germanorum mentio fit non admodum honorifica." Brief Rudolf Agricolas d.J. aus Krakau an Joachim Vadian vom 17. September 1520, in: Die Vadianische Briefsammlung der Stadt- 
Agricola, Aventinus, Celtis und Hessus standen international nicht allein: Insgesamt können an der Wende zum 16. Jahrhundert weitere Stränge einer humanistischen Geschichtsschreibung unterschieden werden, die in ihrer Anlage polnischen Geschichtsbildern kaum Platz einräumten oder identische geographische Räume für konkurrierende Konzepte beanspruchten. Eine italienische Europaund Weltgeschichtsschreibung (Enea Silvio Piccolomini, Macus Antonius Sabellicus) blendete in Piccolomini-Nachfolge die polnisch-litauische Herrschaftsbildung weitgehend aus ${ }^{20}$. Norddeutsche Humanisten wie Albert Krantz suchten die Leerräume einer römisch-italienisch zentrierten Geschichte mit ganz Nordund Osteuropa umfassenden deutsch gefüllten Germania- und Vandalia-Konstrukten zu füllen ${ }^{21}$. Solche Konzepte nahm im 16. Jahrhundert mit nun protestantischer Färbung David Chytraeus auf22.

Polen und der gesamte jagiellonische Reichsverband - der zeitgenössisch ganz Ostmitteleuropa mit der litauischen Großfürstenwürde, der polnischen, tschechischen und ungarischen Krone umfaßte - kamen in diesen Deutungsmustern bis 1520 nur randständig vor. Diese Ausblendung wurde unter führenden polnischen Politikern und Intellektuellen in der Metropole Krakau als geschichtspolitische Herausforderung empfunden. Der Gnesener Erzbischof und polnische Primas Jan Łaski ${ }^{23}$ - einer der einflußreichsten polnischen Politiker im ersten Drittel des 16. Jahrhunderts - beschrieb nach schwierigen Verhandlungen auf dem Laterankonzil in Briefen an den Krakauer Mediziner und Polyhistor Maciej von Miechów

bibliothek St. Gallen, Bd. 2 (St. Gallen 1894) Nr. 216, 308-310; vgl. auch die zahlreichen weiteren Briefe an Vadian, insbesondere der Brief Agricolas vom 25. August 1519: „Clandestinus rumor et iam palam prorepserat de seditione Polonorum Cracoviae contra Germanos; nos itaque omnes instructi eramus." Ebenda 242-245.

20 Zum Blick Piccolominis auf das östliche Europa: Francesco Guida, Enea Silvio Piccolomini e l'Europa Orientale: il „De Europa“ (1458), in: Clio 15 (1979) H. 1 35-77; Ignacy Zarębski, Stosunki Eneasza Sylwiusza z Polską i Polakami [Die Beziehungen Enea Silvios zu Polen und den Polen], (Rozprawy PAU Wydziału Historyczno-Filozoficznego II, 45, Kraków 1939); Bömelburg, Frühneuzeitliche Nationen 44-50.

21 Ulrich Andermann, Albert Krantz. Wissenschaft und Historiographie um 1500 (Forschungen zur mittelalterlichen Geschichte 38, Weimar 1999); Werkanalyse: Viljo Adolf Nordmann, Die Wandalia des Albert Krantz. Eine Untersuchung (Annales Academiae Scientiarum Fennicae B, 29,3, Helsinki 1934).

22 Chytraeus umfangreiches Werk wurde in Polen wenig rezipiert. Dazu beigetragen haben mag, daß die Versuche einer Fortsetzung der Vandalia-Konzeption in nur lose zusammenhängende geographische, annalistische und genealogische Sammlungen mündeten, die keine Struktur deutlich werden ließen, vgl. David Chytraeus, Vandaliae \& Saxoniae Alberti Cranzii continuatio. Ab anno Christi 1500, ubi ille desiit: per studiosum quendam historiarum instituta. Accessit Metropolis (...). Cum Praefatione Davidis Chytraei \& Indice (Wittenbergae 1586). Die neuere Chytraeus-Forschung um Karl-Heinz Glaser hat diese Aspekte bisher nicht aufgegriffen. Chytraeus schrieb zwei Briefe an Sigismund III., die Exemplaren von dessen ohne Autorennennung erschienenem annalistischen Werk Memorabiles aliquot Eventus anni proxime elapsi, MDXCV fideliter annotati. Quibus accesserunt epistolae duae ad Sigismundum III. Poloniae \& Sueciae Regem. (...) Anno MDXCVI. [o. O. Rostock?] 1596 beigefügt waren.

${ }_{23}$ Piotr Tafitowski, Jan Łaski (1456-1531), kanclerz koronny i prymas Polski [Jan Łaski, Kronkanzler und polnischer Primas] (Warszawa 2007). 
(Matthias de Miechow), daß in Rom eigene Positionen schwer vermittelbar seien, da die polnischen Leistungen international nicht bekannt seien. Die Lektüre der „Europa“ und der „Asia“ habe ihm deutlich gemacht, daß bei Enea immer dort, wo der Taten der Polen gedacht werde, diese zugunsten der Deutschen zurückgesetzt würden ${ }^{24}$. Dagegen forcierte der polnische Primas Pläne einer Nationalgeschichte: Darstellungen sollten die Ehre des polnischen Königs wiederherstellen und für zukünftige Generationen - offen blieb, ob im Ausland oder in Polen eine verbindliche Erinnerung schaffen ${ }^{25}$.

Zwischen 1520 und 1560 entstand eine Folge von polnischen Geschichtsentwürfen und -beschreibungen, die schrittweise die Postulate von Łaski einzulösen suchten und eine originäre polnische humanistische Nationalgeschichtsschreibung schufen. Dabei war der Weg historiographiegeschichtlich komplex, denn die vorhumanistische polnische Geschichtsschreibung unter dem Einfluß des umfangreichen Werks von Johannes Długosz (1415-1480) zeichnete insbesondere von den Jagiellonen ein kritisches Bild und war deshalb nur teilweise anschlußfähig. Die 1519 gedruckte Erstausgabe von Maciej von Miechóws Chronica Polonorum, deren Druck Łaski angeregt hatte, wurde deshalb zunächst eingezogen und in den entsprechenden Passagen gesäubert. Hinzugefügt wurden von dem hofnahen elsässischen Humanisten Jodocus Ludovicus Decius - ein weiteres Beispiel für das Engagement deutschsprachiger Humanisten am polnischen Hof - verfaßte Beiträge, die eine Familiengeschichte der Jagiellonen und eine Herrscherlob König Sigismunds beisteuerten. Erst in dieser Form konnte das Geschichtswerk 1521 als erste gedruckte Geschichte Polens erscheinen ${ }^{26}$.

Die in den 1550er und 1560er Jahren in drei Auflagen erschienene polnischsprachige Weltchronik Marcin Bielskis enthielt umfangreiche und von Ausgabe zu Ausgabe ausgebaute Darstellungen zur polnischen Geschichte, die insbesondere

24 „Quum Pii secundi Pontificis alias Aenee Cosmographiam revolverem (nam et de Asie Europeque locis rebusque gestis perscripsit), quotienscunque contingit eum gestorum Polonie meminisse, semper [se] nacioni dignitatique regie Polonie detr[a] haere et germanis in nostrum quoddamvis decedus favere ostendit." Materiały do dziejów dyplomacji polskiej w latach 1486-1516 (Kodeks zagrzebski) [Materialien zur Geschichte der polnischen Diplomatie 1486-1516 (Der Zagreber Codex)], hrsg. v. Józef Garbacik (Wrocław 1966) 185.

25 „Spero enim (...) me consecuturum ut maximo honori regi Reique Publice regni Polonie ex hac re nos fuisse, exnunc sentiant homines et in posteram memoria teneant." Ebenda 186. 26 Maciej von Miechów, Chronica Polonorum (Kraków 21521) Reprint (Kraków 1986) (Anhang: Jodocus Ludovicus Decius, De vetustatibus Polonorum, De Jagellonum familia, De Sigismundi Regis Temporibus); zu Werk und Tätikeit M.s: Maciej z Miechowa 1457-1523. Historyk, geograf, lekarz, organizator nauki [Maciej von Miechów 1457-1523. Historiker, Geograf, Arzt und Wissenschaftsorganisator] (Monografii z dziejów nauki i techniki 15, Wrocław 1960); Leszek Hajdukiewicz, Biblioteka Macieja z Miechowa [Die Bibliothek Maciej von Miechóws] (Monografie z dziejów nauki i techniki 16, Wrocław 1960); Beschreibung des Zensurfalls: Ferdynand Bostel, Zakaz Miechowity [Das Verbot Maciej von Miechóws], in: Przewodnik Naukowy i Literacki 12 (1884) 438-451; 540-562; 637-652; zu Decius fehlt eine moderne Darstellung, verwendbar: Aleksander Hirschberg, $\mathrm{O}$ życiu i pismach Justa Ludwika Decyusza 1485-1545 [Über das Leben und die Schriften des Justus Ludovicus Decius] (Lwów 1874). 
die Lesebedürfnisse des Adels befriedigten und in erheblichem Maße nationale Sichtweisen und Klischees transportierten ${ }^{27}$. Neben der auf den Adel zugeschnittenen Sprache besaß die Darstellung Bielskis durch die Ausführung exemplarischer Episoden und durch Schilderungen mit didaktischem Anspruch große Breitenwirkung. Eine wiederholte direkte Ansprache des Lesers, die Schilderung aus der kollektiven Wir-Perspektive und die ausgiebige Verwendung des Sarmatienund Polen-Begriffs schufen ein hohes Identifikationspotential. In allen drei Ausgaben nahm die nationale Geschichte einen erheblichen Platz ein: In der Ausgabe 1551 umfaßte die polnische Geschichte fast 300 Seiten und mithin über 40 Prozent der Darstellung, so daß Bielskis Weltchronik die erste Geschichte Polens in polnischer Sprache darstellt. Deutlich liegt eine strukturelle Parallele zur wenige Jahre (1544) zuvor erschienenen Kosmographie von Sebastian Münster vor, bei dem die „Beschreibung Teutscher Nation“ einen ähnlichen Anteil am Gesamtvolumen einnahm.

Ein zweites Corpus von Schlüsseltexten wurde in den 1550er und 1560er Jahren von dem königlichen Sekretär und ermländischen Bischof Marcin Kromer verfaßt ${ }^{28}$. Die außerordentliche Wirkung von Kromers De origine et rebus gestis Polonorum libri $X X X^{29}$ und dessen Polonia ${ }^{30}$ war bereits zeitgenössisch unstrittig.

27 In chronologischer Reihenfolge: Marcin Bielski, Kronika wszytkyego śwyata, na ssesc wyekow, Monarchie cztery rozdzielona, s Kosmográphią nową (...) po polsku pisána, s figurámi. (...) Myędzy ktorémi też nászá Polska ná ostátku zosobná yest wypisána [Chronik der ganzen Welt, auf sechs Zeitalter und vier Monarchien aufgeteilt, mit einer neuen Kosmographie, polnisch geschrieben, mit Abbildungen. Darunter ist auch unser Polen endlich gesondert ausgeschrieben] (Kraków 1551); Marcin Bielski, Kronika Wssythego swyata (...). Dostátecznyey, niż pirwssa, spisána (...) [Chronik der ganzen Welt (...). Gegenüber der Erstausgabe verbessert] (Kraków 1554); Marcin Bielski, Kronika, tho iesth Historya Świátá, na sześć wieków á cztery Monarchie rozdzielona z rozmáitych historyków (...) wybierana i na Polski ięzyk wpisana, dosthátheczniey niż pierwey, s przydanim wiele rzeczy nowych: Od początku Swiata aż do tego roku (...) [Chronik, das ist die Geschichte der Welt, auf sechs Zeitalter und vier Monarchien aufgeteilt, aus verschiedenen Historikern ausgewählt und in polnischer Sprache geschrieben, verbessert gegenüber der ersten Ausgabe und unter Hinzufügung vieler neuer Sachen: Vom Anfang der Welt bis auf dieses Jahr] (Kraków 1564) Reprint (Kraków 1976).

${ }_{28} \mathrm{Zu}$ Kromer liegt keine moderne Biographie vor; benutzbar: Anton Eichhorn, Der ermländische Bischof Martin Kromer als Schriftsteller, Staatsmann und Kirchenfürst, in: ZGAE, 4 (1869) 1-470. Einen Einblick in die Kromer-Forschung gibt Bd. 26 (1994) der Studia Warmińskie, der die Ergebnisse eines Symposiums enthält.

29 [Marcin Kromer], De origine et rebus gestis Polonorum libri XXX. Adiecta est in sine, eiusdem autoris funebris Oratio, Sigismundi Regis uitam compendiose complex (Basileae 1555, 21558, 31568); deutsche Übersetzung: Mitnächtischer Völckeren Historien. In welcher viler Nationen als namlich der Polenderen, Slauen (...) Ursprung/mancherley gebreüche/ namhaffte Historien /Regiment /und Ritterliche taathen (...). Erstlich durch den Hochgelerten Herren Martinum Chromer auß Poland zu Latein fleyßig beschrieben: Jetzumalen aber durch Heinrich Pantaleon (...) zu gutem gemeiner Teutscher nation auff das treülichest verteütschet, gemehret, und in truck verordnet (Basel 1562).

30 [Marcin Kromer], Polonia sive situ populis, moribus, magistratibus, et respublica Regni Poloniae libri duo (Colonia 1577). Weitere Ausgaben: Poloniae gentisque et Reipublicae descriptionis libri duo; Erstdruck zusammen mit dem Nachdruck von Albert Krantz, Wandalia 
So schrieb Kromers Studienfreund und Rivale Orzechowski über das Echo auf dessen Schriften: „Er schrieb uns eine Chronik wie ein zweiter Xenophon oder Cäsar; er brachte uns der Welt zur Kenntnis; was für ein Volk wir sind, zeigte er den Ausländern. Zuvor vermuteten voreingenommene Personen, Polen sei eine Stadt wie Bologna in Italien, was wir oft genug zu hören bekamen, wenn wir in der Welt reisten. Der Herrgott klärte uns durch Kromers Feder auf und empfahl uns ausländischen Ländern, so daß uns heute niemand mehr für sittenlos und ungeübt wie früher hält." ${ }^{\text {"31 }}$

Beide Werkcorpora entwickelten durch die gesamte frühe Neuzeit eine starke Ausstrahlungskraft, wobei Bielski insbesondere durch das Polnische eine Breitenwirkung auch unter dem nicht lateinischsprachigen Mittel- und Kleinadel im Großfürstentum Litauen und den ostslavischen Territorien erreichte, während Kromer insbesondere durch die vorbildliche Latinität etwa an den Jesuitenkollegs als Musterautor und Schullektüre galt ${ }^{32}$.

Als verbindende Elemente dieser Geschichtsentwürfe können eine gemeinslavische Konstruktion und die Erfindung einer polnisch aufgefaßten „Slavonica illustrata“ gelten. Gegen die Dominanz der italienischen (Piccolomini, Sabellicus) und in Konkurrenz mit den deutschen Humanisten wurde eine eigene Version der nationalen Geschichte entwickelt. Vor allem wurde jede Abhängigkeit vom Reich zurückgewiesen: „Poloni nunquam fuere tributarii Romano imperii.“33 Diese

(Frankfurt a.M. 1575) ohne Wissen und Autorisierung Kromers in dem insbesondere dem calvinistischen Humanismus verpflichteten Druckhaus Wechelus mit Vorrede an Hubert Languet; zweite, autorisierte Auflage: Colonia 1578; dritte Auflage: Polonicae historiae corpus: Hoc est Polonicarum rerum latini recentiores $\&$ veteres scriptores, quotquot extant (...). Ex bibliotheca Ioan. Pistorii Nidani (...) 3 Bde. (Basileae 1582), Bd. 1 74-120; vierte Auflage: Colonia 1589 (Ausgabe der historischen Werke Kromers); fünfte Auflage: o. O. 1594; weitere Auflagen in der Sammlung Respublica sive status [11626] 21627 31642. Übersetzung ins Spanische: Una breve i sumaria description del Reyno de Polonia colejidia de la Polonia de Martino Cromero obispo de Warmia, por Nicolao Secovio cavallero Polaco. Traduzida de latin en lengua Castellana (Madrid 1588); italienische Überarbeitung: Nicolaus Secovius, Regni Poloniae brevis et compendiosa descriptio e Martino Cromeri „Polonia“ decerpta (Napoli 1582). Übersetzung ins Deutsche 1741 von Andreas Schott, Beschreibung des Königreichs Polen (Leipzig/Danzig 1741). Kritische Ausgabe des lateinischen Textes: Martini Cromeri Polonia sive de situ (...) libri duo 1578, hrsg. v. Wiktor Czermak (Kraków 1901).

31 „Napisał nam krojnike jako Ksenofon albo Cezar drugi; objawił nas światu; co za lud jesteśmy, ludzióm obcym ukazał. Mniemali przed tym postronni ludzie, aby Polonia było miasto jakieś, tak jako jest Bononia we Włoszech miasto jedno, czegośmy się, po świecie jeżdżąc, nasłychawali dosyć. Oświecił nas Pan Bóg Kromerowym piórem, zalecił nas obcym krajom, tak że nas dziś ludzie nie mają za sprosne i niewyćwiczone jako przed tym nas mieli (...)“, in: Stanistaw Orzechowski, Wybór pism [Schriftenauswahl], bearb. v. Jerzy Starnawski (Wrocław 1972) 418.

32 Belege bei Bömelburg, Frühneuzeitliche Nationen 101-127, 225-238.

33 Kromer, De origine (1555) 26-27 u. 67 mit dem zentralen Dictum. Kromer rezipierte übrigens ansatzweise (ab der zweiten Ausgabe wird Helmold genannt) die humanistischen Editionen deutscher mittelalterlicher Chronisten. 
These sollte zum Eckpfeiler des polnischen Geschichtsbewußtseins der frühen Neuzeit werden ${ }^{34}$.

Gegenüber dem - für die mehrheitlich katholischen Autoren schwer angreifbaren - Enea Silvio Piccolomini wurde ein negativer Einfluß der deutschen Umgebung konstruiert: Der Deutsche Orden und die Deutschen hätten eine negative Meinung über Polen an Enea vermittelt; dies könne man bei den deutschen Geschichtsschreibern stets finden ${ }^{35}$. Ähnlich scharf äußerte sich die Kritik an böhmischen Konzeptionen, die man über das Werk Hájek von Libočans rezipierte ${ }^{36}$. Quellen und Behauptungen, die böhmische Einflüsse auf die polnische Geschichte nahelegten, wurden durchweg bestritten.

Weiterhin wurden polnisch-sarmatische Einflüsse bis an die Nord- und Ostsee (angebliche Gründung Bremens, Beherrschung Dänemarks) behauptet. Ältere Mischkonzeptionen wie die von "sarmatischen Vandalen“ oder „sarmatischen Goten“ bzw. das Konzept eines jahrhundertelangen Zusammenlebens von Sarmaten-Polen und Germanen-Deutschen wurden nun verworfen ${ }^{37}$.

Schneidend scharf wurde diese Kritik, wo zu nationalen Argumentationslinien der konfessionelle Faktor hinzutrat. Der protestantische Mediziner Joachim $\mathrm{Cu}-$ reus hatte in der ersten gedruckten Geschichte Schlesiens versucht, eine germanische Frühgeschichte zu etablieren und schlesische Ortsnamen auf germanische Wurzeln zurückzuführen ${ }^{38}$. Dies verband er mit einer grundsätzlichen Infrage-

34 Einige Belege: Stanistaw Lubieński, Opera posthuma, historica, historo-politica, variique discursus, epistolae, et aliquot orationes (...) (Antverpiae 1643) 175: „Poloniam ab illo [Carolo Magno, H.-J.B.] fuisse subjugatam, nemo vere dixerit; idem enim ostendere deberet, quo tempore Polonia iugum imperii excusserit." Andrzej Maksymilian Fredro, Scriptorum seu togae \& belli notationum fragmenta. Accesserunt Peristromata Regum Symbolis expressa (Dantisci 1660) 236: „Nunquam Poloni vinci aut frangi possunt, nisi prius ipsi contra se armentur.“

35 Kromer, De origine (1555) 551: „impensius indulgente Cruciferis \& Germanis pontifice iam inde ex quo in aula \& ministerio Friderici Imperatoris fuerat. Quorum fortassis opera \& odio in Polonos perfectum est, ut is nunquam de Polonis bene sentiret: quod e scriptis eius cuisque deprehendere licet."

36 Kromer, De origine (1555) 55-57 u. 60.

37 Kromer, De origine (1555) 3-4, 7-10 u. 18. Die Ausgabe 31568 verschärfte die Kritik an der deutschen Geschichtsschreibung noch: „Cumque Germani homines (nam hi fere sunt in hac sententia) iure suo (...) ad amplitudinem \& gloriam nationis suae pertinere iudicantes, ne ea Vandaliae ac Boemiae antiquissima possessione, a noua \& obscura gente Slauorum, qui nec ipsi certam originem sam edere possent."

38 Joachim Cureus, Gentis Silesiae Annales complectentes historiam de origine, propagatione et migrationibus gentis (...) (Witebergae 1571); ders., Schlesische General Chronica, Darinnen Warhaffte eigentliche und kurtze Beschreibung / Des Landes Ober- und Nider Schlesien (...). o. O. 1585. Zu Cureus vergleichend Matthias Weber, Zur Konzeption protonationaler Geschichtsbilder. Pommern und Schlesien in geschichtlichen Darstellungen des 16. Jahrhunderts, in: Die Konstruktion der Vergangenheit. Geschichtsdenken, Traditionsbildung und Selbstdarstellung im frühneuzeitlichen Ostmitteleuropa, hrsg. v. Joachim Bablcke, Arno Strobmeyer (Zeitschrift für Historische Forschung Beiheft 29, Berlin 2002) 55-79. Cureus' Darstellung dominierte die protestantische schlesische Landesgeschichtsschreibung bis zum Dreißigjährigen Krieg, so in den Veröffentlichungen von Jacob Schickfuß. 
stellung polnischer Geschichte ${ }^{39}$ und einer negativen Konnotierung slavischer Traditionen in der schlesischen Geschichte. Erst die Deutschen hätten „gute Künste und höfliche Sitten" eingeführt ${ }^{40}$. Dagegen schlug Marcin Kromer zurück: Cureus habe in seinen offensichtlich haltlosen und zusammengeschriebenen Schriften böswillig und verleumderisch das polnische Volk und dessen Geschichte angegriffen ${ }^{41}$.

Das Konfliktpotential humanistisch-rhetorisch aufgeladener Konstrukte einer germanisch-deutschen Germania magna bis zur Weichsel oder einer sarmatischpolnischen Sarmatia magna bis zur Oder und Weser wird in dieser Polemik plastisch spürbar. Sie ist im Falle der Kontroverse Cureus-Kromer durch die ganze Frühe Neuzeit von späteren polnischen und schlesischen Autoren fortgeführt worden.

Ein Zwischenfazit: Zwischen 1500 und 1550 entstand eine beziehungsgeschichtliche Dimension, in der sich als "polnisch“ definierende Humanisten und Intellektuelle nationale Konstrukte in deutlichem Bezug auf einen zunächst als „italienisch“ und dann vor allem als „deutsch“ verorteten Gegenpart entwickelten. Das frühneuzeitliche polnische Geschichtskonstrukt entwickelte sich aus der Abgrenzung und Bezugnahme auf deutsche Autoren und deren national verortete Geschichtsentwürfe. Die böhmischen Einflüsse in Kleinpolen, die prätendierte Vorrangstellung des Kaisers oder die Regierung einer litauischen Dynastie über mehr als 150 Jahre, solche Faktoren wurden minimiert. Durch diese Abgrenzung wurde zudem eine Abschließung des eigenen Geschichtsbildes gegenüber als apokryph ausgegrenzten und andersnationalen Interpretationen erzielt.

39 Cureus, Gentis Silesiae Annales, Praefatio (in der späteren deutschen Ausgabe weggelassen): „Discedo interdum a narrationibus scriptorum Polonicorum, cum videam, res illas aliter \& probabilius recitas esse a Germanis. Et manifestum est, non solum negligentiam fuisse veterum historicorum in istis populis magnam, sed eos etiam saepe niminum affectibus indulsisse. Eque vero aliquis suspicabitur, me odia gentis illa immutasse, quia ego gentem Polonicam ortam a noblissima \& antiquissima stirpe Heneta maxime veneror (...). Et huic Regno, quod tot seculis a ceruicibus nostris arma Scythica \& Moscouitica arcet, tota Europa debet gratiam, \& inprimis Silesia, quae colonia \& filia est huius Regni (...).“ Vgl. auch S. 3: „Tandem vero, vbi Silesia desertis Polonis coniunxit se cum regno Bohemiae, illi quidem mutili historici eam ex suis chroncis quasi relegant“; Randbemerkung: „Historiae Silesiae in chronicis Polonicis sunt mutilae."

40 Cureus, Schlesische General Chronica 133, vgl. auch 99-100, 106-108. In der lateinischen Fassung noch schärfer, vgl. Cureus, Gentis Silesiae Annales 74: „sicut non dubium est, hanc regionem tunc primum culturam accepisse. Accersivit ex Germania multas familias, qui novi coloni literas \& humanitatem simul huc intulerunt."

41 Kromer, Polonia 5-9, 11; hier 5: „Qui quamvis sedulo dissimilare studeat, quo animo scripserit et unde pleraque omna compilarit, prodit tamen sese petulans eius malevolentia et maledicentia (...) quam gentem Polonam omnem (...) et res gestas eius deprimere et insectari sibi proposuit." Hintergrund der Auseinandersetzungen ist auch die verdeckte Kritik von Cureus an Kromers De origine und der Vorwurf an letzteren, er habe nur Długosz ausgeschrieben. Die Polemik wird bei Hermann Markgraf, Die Entwickelung der schlesischen Geschichtsschreibung, in: Zeitschrift des Vereins für Geschichte und Alterthum Schlesiens 22 (1888) 1-24, hier 3-4 behandelt. 


\section{Die deutsche Nation in der Publizistik der polnischen Interregna 1572/87}

Öffentlich wirksam wurden diese Vorstellungen in der polnischen Publizistik der drei Interregna zwischen 1572 und 1587. Kristallisationspunkte bildeten die habsburgischen Kandidaturen in allen drei Interregna: Zwei Drittel der etwa 100 bekannten Texte durchzieht eine Positionierung gegen die als „deutsch“ aufgefaßten Habsburger, die auf antideutschen und antiböhmischen Argumentationslinien aufbaute $^{42}$. Einerseits wurden deutsch-polnische und böhmisch-polnische Konflikte aufgegriffen, deren Fazit in memorierbaren und plastischen Merkversen präsentiert wurde ${ }^{43}$. Gewicht besaßen Exempellisten aus dem nationalen Geschichtskanon, in denen Fälle skizziert wurden, wo deutsche Eliten der polnischen Nation Schaden zugefügt hätten ${ }^{44}$. Einsetzend mit der mythischen Herrscherin Wanda, die eher Selbstmord begangen hatte, als einen Deutschen zu heiraten ${ }^{45}$, „schlechte“ piastische Herrscher, die von ihren deutschen Frauen und deut-

42 Diesen Sachverhalt hatte wohl Janusz Tazbir im Sinn, als er formulierte: „A sedno sprawy polegało na tym, że choć szlachtę często straszono ponurą wizją tureckiej okupacji, to w gruncie rzeczy bardziej obawiała się Habsburgów “ [Der Kern liegt darin, daß, obwohl der Adel oft mit der finsteren Vision einer osmanischen Herrschaft aufgeschreckt wurde, er im Grunde die Habsburger mehr fürchtete], in: Janusz Tazbir, Polskie przedmurze chrześcijańskiej Europy [Die polnische Vormauer des christlichen Europas] (Warszawa 1987) 38.

43 Zitiert wurde beispielsweise in abgewandelter, gereimter Form der berühmte Merkspruch „Póki świat światem (...)“: „Inszych się prze Bóg, strzeżmy, bo póki świat światem, Obcy wilk, a nam Deutsch na pewne źle bratem“ [Hüten wir uns um Gottes Willen vor Fremden, denn solange die Welt besteht, ist ein Fremder ein Wolf und uns der Deutsche sicher ein schlechter Bruder], in: Pisma polityczne z czasów pierwszego bezkrólewia [Politische Schriften aus dem ersten Interregnum], hrsg. v. Jan Czubek (Kraków 1906) 32-33; „między Niemcy a Polaki jakaś wrodzona niezgoda jest " [zwischen Deutschen und Polen gibt es eine angeborene Zwietracht], in: ebenda 397-403, hier 402; ähnlich ebenda 404-408, hier 405, 407; „nic mem zdaniem na to oglądać nie trzeba, iż między Niemcy a Polaki jakoby przyrodzona jakaś dyssenza z dawna się pokazuje, bo to od początku świata i po wszem świecie tak zawżdy bywał" [meiner Meinung nach muß man darauf keinen Wert legen, daß zwischen den Deutschen und den Polen eine angeborene Zwietracht sich von alters her zeigt, denn so war es von Anfang der Welt und auf der ganzen Welt immer], ebenda 429-438, hier 435 (Entkräftungsversuch von prohabsburgischer Seite). Der Deutsche Orden als negatives Beispiel für den Einfluß deutscher Eliten tauchte dagegen nur selten auf, vgl. ebenda 460, 463. In dem wohl umfangreichsten Beitrag zur Genese des Merkspruchs ist gerade die Publizistik der Interregna gänzlich ausgespart, was dessen Ergebnisse in Frage stellt, vgl. Gerard Labuda, Geneza przysłowia: "Jak świat światem, nie będzie Niemiec Polakowi bratem" [Der Ursprung des Sprichworts „Solange die Welt die Welt ist, wird der Deutsche dem Polen kein Bruder sein"], in: Zeszyty Naukowe Uniw. im. Adama Mickiewicza, Historia 8 (1968) 17-32.

44 „Gdyby panowie Polacy cesarza albo Niemca obrali, toby na nie przyść musiało“ [Wenn die Herren Polen den Kaiser oder einen Deutschen wählten, was daraus resultierte], in: Pisma polityczne 358-362.

45 „Z dawna się Polacy Niemcy brzydzili, a pewnie nie bez przyczyny, chociaż Niemcy nad nimi panować jeszcze od początku chcieli: złudzony to naród a przewrotny. (...) królewna Wanda, gdy do niej Niemiec jacha, wolała się sama utopić, niżli za Niemca iść. Caeterum nie dawna rzecz, gdy rakuskie książę już miało przychylność królowej Jadwigi sponsati beli: 
schen Beratern mißgeleitet worden seien ${ }^{46}$, über den habsburgischen Ehekandidaten Wilhelm, der vor Jagiełło aus Krakau geflohen sei; stets hätten unter deutschem Einfluß stehende Herrscher und deren Hof polnische Interessen verraten ${ }^{47}$. Die polnische Krone habe zahlreiche Territorien an deutsche Herrscher verloren - verwiesen wurde auf Schlesien ${ }^{48}$. Angeführt wurde ebenfalls eine angeblich dauerhafte Rivalität zwischen der „Polonia“ und der „Germania“49.

Neu taucht in den Debatten der 1570er Jahre das Argument der abweichenden politischen Ordnung auf: Deutsche Herrscher tendierten dazu, adlige Freiheiten $\mathrm{zu}$ beschneiden und eine tyrannische Herrschaft zu installieren - hier folgte wiederholt ein Verweis auf das habsburgische Vorgehen nach dem böhmischen Ständeaufstand von $1547^{50}$. Bei diesen Äußerungen wurde ein abweichender Charak-

polacy przecię o innym panie, jako o Jagielle, radzili." [Von alters her empfanden Polen und Deutsche voreinander Abscheu, und sicher nicht ohne Grund, wenigstens wollten die Deutschen anfangs über sie herrschen: diese sind eine gauklerische und hinterlistige Nation (...) die Königin Wanda, als zu ihr ein Deutscher reiste, zog es vor sich zu ertränken, als einen Deutschen zu heiraten. Es ist übrigens keine alte Sache, denn als ein österreichischer Herzog schon die Gunst der Königin Jadwiga genoß und sie verlobt waren, rieten die Polen dagegen zu einem anderen Herrn, nämlich Jagiełło], ebenda. Das Wanda-Motiv wurde auch in der polnischen Publizistik des 17. Jahrhunderts wiederholt aufgegriffen, Belege bei Andrzej Lipski, Społeczeństwo a historia. Czasy Zygmunta III Wazy [Gesellschaft und Geschichte. Die Zeit Zygmunt III.], (Diss. Warszawa 1984) 348, 393; Andrzej Zbylitowski, Droga do Szwecji Króla J. Mości w r. 1594 [Erstdruck Kraków 1597], in: Andrzej Zbylitowski, Piotr Zbylitowski: Niektóre poezje [Einige Gedichte], hrsg. v. K. J. Turowski (Kraków 1860) 8; Andrzej Zbylitowski, Epithalamium na wesele (...) Zygmuntowi III (...) i arcyksiężnie J.M. rakuskiej Annie (1592) [Epithalamium zur Hochzeit Zygmunt III. mit der österreichischen Erzherzogin Anna (1592)], hrsg. v. J. Łoś (Kraków 1893) 6: „slavische Nymphe“ (Nimfa słowieńska); Ryszard Łużny, Pisarze kręgu Akademii Kijowsko-Mohylańskiej a literatura polska [Schriftsteller aus dem Kreis der Kiever Mohyla-Akademie und die polnische Literatur], (Zeszyty Naukowe Uniwersytetu Jagiellońskiego 142; Prace historycznoliterackie 11, Kraków 1966) 57 „Wanda mężna rządziła Polaki cnotliwy, / Poraziła Niemce, nam zdawna niechętliwe" [Wanda regierte männlich die tugendhaften Polen und brachte dem uns von alters her abgeneigten Deutschen eine Niederlage bei].

46 Sentencya cuisdam de electione regis Polonorum cum commonstratione commodi et incommodi inde emergentis, in: Pisma polityczne 362-381, hier 365 über die angebliche Gattin von Władysław II. namens Krystyna (tatsächlich Agnieszka).

47 „Z narodu niemieckiego, nam zawżdy przeciwnego“" [aus der deutschen Nation, die gegen uns immer feindlich eingestellt war], in: ebenda 492-494, hier 492.

48 „Co sie z kronik łacno pokaże. Atoż za tymi przyczynami od Miemców wolni być nie możemy, a snaćby sie tego i więcej znalazło (...) bo nie małą krzywdę cierpi Korona polska od Miemców w posiadaniu gruntów" [was sich aus den Chroniken mühelos zeigen läßt. Aus diesen Gründen können wir von den Deutschen nicht frei sein, und vermutlich ließe sich dazu noch mehr finden (...) denn kein geringes Unrecht erleidet die polnische Krone von den Deutschen bei dem Besitz von Territorien], in: ebenda 381-397, hier 391.

49 „Dłużej Polska w tym nierządzie, jako go zową, stała et floruit, et Germania w onym swym wielkim rządzie kilkakroć przewróciła kozłek" [Polen hat länger in seiner Unordnung, wie sie es nennen, bestanden und geblüht, und die Germania in jener, ihrer großen Ordnung mehrfach Purzelbäume geschlagen], in: ebenda 454-458, hier 458.

50 Ebenda 28, 344-345, 358-362, 439-440; „Ano zawsze abhorruit naród nasz od panowania niemieckiego “ [Unsere Nation schreckte immer vor einer deutschen Herrschaft zurück], in: ebenda 632-633, auch 635-636; „A więc ta święta wolność y to Polska cnota, którą się my 
ter der deutschen Nation aus der unterschiedlichen ständischen Zusammensetzung der Eliten konstruiert: Die Deutschen seien „Taktierer und Kaufleute“ und hätten für die polnische Ordnung kein Verständnis ${ }^{51}$.

Weniger eindeutig blieb die Stereotypisierung der Böhmen, die durch die gemeinsame Herkunftserzählung als Brudervolk galten und immer als Slaven aufgefaßt wurden (es gab in der frühneuzeitlichen polnischen Optik keine deutschen Böhmen). Dennoch wurde die Vorstellung eines böhmisch-polnischen Antagonismus entwickelt ${ }^{52}$, der zeitgenössisch gegen die Habsburger als die Inhaber der böhmischen Krone gerichtet war. Im Gegenzug suchte die habsburgfreundliche Panegyrik diesen eine Abkunft von Czech zuzuschreiben, um die gegnerischen Argumente zu entkräften ${ }^{53}$.

$\mathrm{Zu}$ beachten ist die Reichweite der polnischen Publizistik der 1570er und 1580er Jahre: Durch Wiederholungen und vielfache Abwandlungen konnte eine Verfestigung erreicht werden, die die Wahrnehmung der deutschen Könige und Fürsten als potentiell „tyrannisch“ festschrieb und sich auf einen Kanon von Exempla stützte. Alle Adligen, die an den Wahlen teilnahmen - geschätzt werden für die Interregna dieser Jahrzehnte 6000-7000 (1573), 12000 (1575) bis 20000 (1587) Teilnehmer, kamen mit der Publizistik in Berührung ${ }^{54}$. Es erscheint deshalb nicht überzogen, eine Diffusion unter den gesamten adligen Eliten PolenLitauens zu postulieren.

chłubimy (...). Aleć oni tym czasem na Niemca wotuią (...), bo co on Król święty / Począł scinać, to Niemiec między nimi wzięty. " [Diese heilige Freiheit ist eine polnische Tugend, der wir uns rühmen (...). Aber jetzt stimmen sie für einen Deutschen (...) was für ein heiliger König ist er; er fing an Köpfe abzuscheiden, dieser aus unseren Reihen gewählte Deutsche], aus: Brevis sed verissima invectiva (1587), in: Biblioteka Czartoryska, rkps. 328 33-35.

51 „Bo Niemcy serca nie mają, są praktykowie, kupcy, delikaci i hardzi (...). Panowie Polacy, cavete od Niemca" [Denn die Deutschen haben kein Herz, sie sind Taktierer, Kaufleute, delikat und kühn (...). Meine Herren Polen, hütet euch vor dem Deutschen], in: Pisma polityczne 360-361; „zawżdy to Polakom dobrze, co Niemcom źle, et contra. (...). A za nie peregrinus Polakowi Niemiec? Prosto tak z sobą zrośli, jako wilk z jagnięty. “ [was für die Polen gut war, war für die Deutschen schlecht, und umgekehrt. (...) Und erwächst nicht aus dem Zugereisten dem Polen ein Deutscher? Sie sind miteinander verschmolzen, wie der Wolf mit dem Lamm], ebenda 463; Urteil über die Deutschen „naród nędzny, chciwy i łakomy“ [ein erbärmliches Volk, habgierig und unersättlich], ebenda 472; „Bo niektórzy widzę o tym odiose mówią, czego ja nie chwalę, że między Polaki a Niemcy na wieki zgoda być nie może, jedno, aby sie nad nimi pomścili przeszłych wojen i despektów. (...) Niemiec Polakom nie może być pożyteczny, i owszem szkodliwy, prze to blizkie sąsiedztwo " [Ich sehe, daß manche darüber haßerfüllt sprechen, was ich nicht billige, daß zwischen Polen und Deutschen über Jahrhunderte keine Eintracht herrschen könne, nur das eine, daß man sich an ihnen für die früheren Kriege und die Mißgunst rächen müsse. (...) der Deutsche kann dem Polen nicht nützlich sein, sondern wegen der nahen Nachbarschaft schädlich], ebenda 482.

52 Ebenda 364-365: Königswahl von Wenzel und dessen Herrschaft.

53 „Niepodobne braterstwo! Jeśliż niepodobne / Lecha z Czechem świat zowie?" [Ungleiche Bruderschaft! Wenn ungleich, wie nennt die Welt die Verbindung von Lech und Czech?], aus: Lutnia na wesele (...) Zygmunta III (...), in: Jan Jurkowski, Dzieła wszystkie [Sämtliche Werke], Bd. 2 (Wrocław 1968) 207.

54 Schätzungen der Teilnehmer nach Jan Dzięgielewski, Sejmy elekcyjne, elektorzy, elekcje 1573-1674 [Die Wahlsejme, Wähler und Wahlen 1573-1674] (Pułtusk 2003) 70-72. 
Im Vergleich besaßen diese antideutschen und antiböhmischen Konstrukte nicht die Schärfe der konfessionell und kulturalistisch aufgeladenen antitürkischen und antimoskowischen Feindbilder. Es fehlte die Ebene der Ausgrenzung als „Barbaren“, während dagegen der verfassungspolitische Vorwurf einer „tyrannischen Herrschaftsform“ gegen die Deutschen Parallelen mit dem polnischen Moskaubild aufweist.

\section{Konfessionell, dynastisch und verfassungsrechtlich geprägte Ordnungsvorstellungen von „deutsch“ und „Deutschland“ in Polen-Litauen}

Nach 1587 wurde Polen-Litauen für mehr als ein halbes Jahrhundert durch einen mehrheitlich deutschsprachigen Wasahof regiert. Zugleich gewannen nach der Zurückdrängung der Reformation dezidiert nationalkatholische Perspektiven an Gewicht. Durch die Unbeliebtheit der Wasakönige und im Lichte der scharfen Hofkritik verfestigte sich auch das kritische Bild von der deutschen Nation insbesondere in der antihöfischen Opposition.

Einen Höhepunkt erreicht diese Verbindung von konfessioneller und nationaler Ablehnung bei dem Bischof von Przemyśl Paweł Piasecki: Aus nationalkonfessioneller Optik wird der Protestantismus als „deutsche Ketzerei“ scharf abgelehnt. Zugleich erscheinen Übernahmen aus dem deutschen Raum als untragbar, da die Andersartigkeit und Wankelmütigkeit der „deutschen Eidechsen“ Gefahr bringe ${ }^{55}$. Der Warschauer Wasahof sei dieser Gefahr bereits erlegen; neue Grundsätze seien dort mit der in der Nation unbeliebten deutschen Sprache eingezogen, was die öffentliche Meinung gegen den König aufbringe ${ }^{56}$. Jedoch sei der „deutsche Protestantismus“ an der polnischen Treue zur alten Religion gescheitert ${ }^{57}$.

55 „Dum igitur vixit priscit patriis moribus, facile venena illa Germanica evitavit, \& severioribus usq. legibus damnavit, regnante in Polonia Sigismundo I (...). Rex [Zygmunt August] enim ipse inter manus alienigenarum enutritus, ad eos eorumq. institutem fuit propensior, \& licentiosiorum vitam agens, in Catholica pietate colenda remissior. Quod autem deterius, inclinator erat ad scientias curiosas, in eisq. utebatur opera Germanorum haereticorum, qui familiaritate Regis securi, liberius errores suos divulgabant, ut non pauci ex Regiis (...) non inviti, nec segniores Ecclesiastici Regis in exemplum concederent. Plurimi etiam Germani origine, quaesitis domiciliis \& cognationibus in Polonia, opibus \& potentia sub illud tempus succreverant, Germanica sua proclivitate, ut Aethiops pelle, nec in Nepotibus immutata." Pawet Piasecki, Chronica gestorum in Europa singularium a Paulo Piasecio Episcopo Praemisliensi (...) (Cracoviae 1645) 48. Vgl. Adam Szelagowski, Paweł Piasecki historyk polski XVII wieku [Paweł Piasecki, ein polnischer Historiker des 17. Jh.s] (Lwów 1899) 54-55.

56 Piasecki, Chronica gestorum (1645) 172 formulierte aus Anlaß des Todes der letzten Jagiellonin Anna „Cum ea non genus solum illud Regium, sed et omnis Aulae Poloniae mos antiquus ac Maiestatis decor interiit, cum Principibus novis Germanis subrepente germanismo genti isti ingrato et adverso. Quo non parum offenderat animos popularium Rex Sigismundis (...)“.

57 Ebenda 50. 
Bedrohlich sei aus dem deutschen Bereich weiterhin der Einfluß des Hauses Habsburg und dessen „tyrannische“ Ziele (servitus haereditia) ${ }^{58}$. Deshalb dürfe kein Deutscher zum König erwählt werden ${ }^{59}$.

Die Reichweite solcher immer wieder vorscheinender Positionen im 17. Jahrhundert ist schwer abzuschätzen, da die katholischen Eliten mehrheitlich in den habsburgischen Kaisern außenpolitische Bündnispartner sahen. Andererseits erschien Piaseckis Darstellung in vier Auflagen (Piasecki, Chronica 1645; weitere Auflagen: 1645, 1648, Amsterdam 1649). Es handelt sich wohl um eine Minderheitenposition, die aber bei Bedarf - etwa in den Königswahlen der Interregna mehrheitsfähig wurde und in der republikanisch-nationalkonfessionellen Publizistik des 17. Jahrhunderts Rezeption fand. So heißt es in der Krise nach dem schwedischen Einmarsch 1655: Die polnischen Eliten hätten die „polnische Freiheit“ - eine Gabe der Königin Polens, der Gottesmutter Maria - mißachtet und sich dem "Joch der deutschen Herrschaft" an den Hals geworfen ${ }^{60}$. Auch die Schweden erscheinen hier als Teil deutscher Ordnungsvorstellungen.

Die Wahrnehmung der Deutschen wurde zudem durch publizistische Debatten im Umfeld der „descriptio gentium“-Literatur geprägt. Die im protestantischen Milieu von dem Tübinger Juristen Thomas Lansius (1577-1657) herausgegebenen und stark konfessionell gefärbten „Orationes (...) de Principatu inter Provincias Europae“ (1613), in denen in rhetorisch aufgebauter Rede und Gegenrede die Vorund Nachteile einer jeder Nation dargestellt wurden 61 , fanden aufgrund des

58 Ebenda 71: „Suspectim enim est Polonis nomen Germanorum, ut qui natura Vatinianum odium erga gentem Slavonam gerunt, eiusque vastissimas Pomeraniae Provincias ad Albim fluvium (ut etiam Germanici Historici testantur, \& plurima loca cognomina idiomatis Slavonici ibi adhuc retinerent) usque protensas, olim ademerunt, \& recenter Austriaci istius gentis Regnum Boemorum liberum acceptum, in turpem servitutem absoluti hereditariique Dominatus contra fidem datam induxerunt." Vgl. auch ebenda 41, 263.

59 Ebenda 71: „Germanum Regem eligi non debere“.

60 „Obdarzyłam ie wolnosćią taką / iakiey okolicznych narodow najwyższych tytułów Panowie nie maią, a oni ią nizacz [ = za nic] sobie maiąc / Niemieckich rządów iarzmo na szyię swoię zaciągnęli.“, in: Szymon Starowolski, Lament utrapionej Matki Korony Polskiej, iuż iuż konaiącey, na syny wyrodne, złośliwe y niedbaiące na Rodzicielkę swoię [Klage der kummervollen Mutter, der Krone Polen, kurz vor dem Dahinscheiden, über ihre entarteten und bösen Söhne, die nicht für ihre Ernährerin sorgen], o. O. o.J. [Kraków 1655/56], Bl. A2v. Das Werk erlebte zahlreiche Folgeauflagen, u. a. auch im Jahre der Zweiten Teilung Polen-Litauens 1793.

61 Thomas Lansius, Orationes seu Consultatio de Principatu inter Provincias Europae, (11613) [Amsterdam] 1637. In dieser Ausgabe finden sich die Reden Pro Polonia 439-457 und Contra Polonia 458-478. Vertreten waren weiterhin die Germania (zwei Pro- und eine Contra-Rede); Gallia (1/1), Hispania (2/1), Hungaria (1/1), Britannia (2/1), Polonia (1/1) und Italia (1/1). Bemerkenswert ist, daß Polen unter den erstrangigen europäischen Nationen vertreten war, während Schweden oder Moskau fehlten. Den „Sieg“ trug selbstverständlich die Germania davon „sed Germanos veneror supra alios populos omnes“, deren Lobredner von dem Württembergischen Landesherrn Friedrich Achilles ausgezeichnet wurde. Daß das Ergebnis des „Wettbewerbs“ bereits zuvor feststand, belegt die Auswahl der (fiktiven) Lobredner: Die einleitende Rede auf die Germania wurde von Franz Karl, dem Sohn des Herzogs Sachsen-Lauenburg und Verwandten des württembergischen Landesherrn Friedrich gehalten. Zu Lansius: ADB, Bd. 17700. 
wachsenden Interesses an einer vergleichenden europäischen Staatenkunde und Völkertypologie europaweit großen Absatz und wurden auch in der sich neu entwickelnden Staatslehre rezipiert. Öffentliche Reaktionen in Polen lösten topoihafte Schilderungen der Landesnatur aus, die „misera \& barbara, horrida \& frigida" sei und wo jeder König nur ein Schatten seiner eigentlichen Bestimmung bliebe62. Die Argumentation griff auf das Urteil des Juristen Henning Arnisaeus $(† 1636)$ zurück, der dem polnischen Monarchen eine in der Verfassungsstruktur untergeordnete Stellung zugeschrieben hatte ${ }^{63}$.

Gegen dieses Wiederaufleben des Barbarentopos und Kritik an den polnischen Herrschern bildete sich in Polen die Texttradition einer "Verteidigung Polens" aus, der namhafte deutsch- und polnischsprachige Autoren zugerechnet werden müssen ${ }^{64}$. Eine erste Gegenrede findet sich bereits 1621 bei dem Absolventen des Danziger Akademischen Gymnasiums Jakob Gadebusch, wobei erneut preußische Stimmen zugunsten Polens intervenieren. Mit Rückgriff auf Melanchthon ${ }^{65}$ wurden die Geschichte, die militärischen Tugenden und die auf Ausgleich angelegte polnische Verfassung gegen „Verleumder" (obrectatores) verteidigt ${ }^{66}$.

\section{Konfligierende rechtshistorische Schulen in Deutschland und Polen nach 1650}

Fortgeführt wurde diese Diskussion durch Hermann Conring und dessen rechtshistorische Schule sowie Widerlegungen von polnischer Seite. Conring hatte sich bereits vor 1655 mit der polnischen Geschichte beschäftigt und war auf der Basis der älteren Quellen zur Reichsgeschichte zu einer ausgesprochen kritischen Bewertung der polnischen Frühgeschichte und zur Akzentuierung der These von

\footnotetext{
62 Lansius, Orationes seu Consultatio 478: „ejus Rex est umbratilis“.

63 Ebenda 477-478: „Ex qua gentis insolentia \& barbarie haud dubie profectum \& illud est, quod fere soli mortalium ex regionibus longinquis Reges sibi adsciscunt; quasi nulli apud eos imperio digni nasceretur; (...) Rex Poloniae nihil aliud est, quam os quoddam regni vestri, vobiscum conjunctum, libero ac legitimo vestro suffragio; ut is prorsus nihil agat, nihil moliatur, ac ne loquatur quidem, nisi id, quod ex intimo sensu vestro publice sit profectum." $\mathrm{Zu}$ Arnisäus' Urteil über Polen vgl. Horst Dreitzel, Protestantischer Aristotelismus und absoluter Staat. Die „Politica“ des Henning Arnisaeus (ca. 1575-1636) (Wiesbaden 1970) 225-227, 267-269, 294-296.

64 Stanistaw Kot, Polska złotego wieku a Europa. Studia i szkice [Polen im goldenen Jahrhundert und Europa. Studien und Skizzen], hrsg. v. Henryk Barycz (Warszawa 1987) 101127.

${ }^{65}$ Jacob Gadebusch, Encomium Regni Poloniae (...) conscriptum (...) (Dantisci 1621), Bl. $\mathrm{A} 2 \mathrm{v}-\mathrm{A} 3 \mathrm{r}$.

66 Ebenda, Bl. B1v-C3 mit der Schlußfolgerung: „ita excellit Regnum Poloniae ut Europaeis aliis parum vel nihil cedat.“ (Bl. B4r) Ähnlich Bl. C3v: „hoc Poloniae Regnum, ut sicut hactenus ita porro vigeat, vireat, floreat, mutusque sit vicinorum Regnorum adeoque \& Germaniae."
} 
der mittelalterlichen Abhängigkeit Polens vom Reich gelangt ${ }^{67}$. Dabei konnte er sich auf die umfangreichen Wolfenbütteler und Helmstedter Bibliotheksbestände stützen, die zeitgenössisch außerhalb Polens die weltweit umfangreichsten Sammlungen von polnischen Quellenwerken und Geschichtsschreibern bereithielten. Seit 1655 verfaßte und inspirierte Conring mit schwedischen Geldern eine große Zahl anonymer Flugschriften und Drucke ${ }^{68}$, die den schwedischen Einmarsch in Polen-Litauen mit militärischen (Gefahr durch die mit Polen verbündeten Tataren und den unberechenbaren Moskovitern für das Reich) ${ }^{69}$ und historischen Argumenten $^{70}$ in den Augen einer mitteleuropäischen und internationalen Öffentlichkeit zu rechtfertigen suchten.

67 Hermann Conring, De Germanorum imperio Romano (Helmstedt 1644); Hermann Conring, De finibus Imperii Germanici libri duo. Quibus jura Finium a primo Imperii exordio ad haec nostra usque tempora propugnantur (Helmestadii 1654), Caput XVIII, 307-339: Poloniam ab Ottonis Magni aevo ad Friderici II tempora, pene semper, \& subiectam \& tributariam fuisse Imperio Germanico.

68 Bester Überblick auf der Basis der Bestände in der SUB Göttingen und in Wolfenbüttel; anonyme Publikationen von Hermann Conring, Cyriaci Trasymachi De justitia armorum Svecicorum in Polonos, perq[ue] ea liberata a magno periculo Germania: Ad Andream Nicanorum epistola (Lipsiae [auch Stettin und Helmstedt] 1655); Übersetzung ins Deutsche: Epistola oder Sendschreiben / des Cyriaci Thrasymachi, Von der gerechten Kriegs-Armatur der Cron Schweden wieder die Cron Polen / und von dem dadurch aus grosser Gefahr erretteten Teutschlande An Andream Nicanorem (...). o. O. 1656; leicht veränderte Fassung: Cyriaci Thrasymachi Send-Schreiben / An seinen Freund Andream Nicanor ober zwo Fragen / 1. Ob der jetzige Schwedische Krieg wieder Polen in Gerechtigkeit begründet. 2. Ob selbiger dem Römischen Reich vorständig seye / und wie er Teutschland von einer schweren Forcht befreye? (Hamburg 1656); weiterhin Brevis ac praeliminaris Enumeratio Causarum, ob quas (...) D. Carolus Gustavus, Suecorum, Gothorum, Vandalorumque Rex (...) coactus est Regem Poloniae bello adoriri (Stetini 1655) [erneut Helmestadii 1656]; Übersetzung ins Deutsche: Kurtze Praeliminar-Erzehlung der jenigen Ursachen, welcher wegen der (...) Herr Carl Gustav, der Schweden, Gothen und Wenden König, (...) bewogen und gezwungen worden, den König von Polen mit Heeres-Macht zu uberziehen. o.O. 1655; Ecclipsis, der Elbingschen Beleuchtigung über die Antwort Andreae Nicanoris auff des Cyriaci Trasymachi Epistel von Ungerechtigkeit der schwedischen Waffen wieder das Königreich Pohlen. o.O. 1656. Nach Nathan Goldschlag, Beiträge zur politischen und publizistischen Thätigkeit Herman Conrings (Diss. Göttingen, Berlin 1884) 34 sind weitere drei deutsche Fassungen und eine niederländische Übersetzung aus der Feder Conrings erschienen. Auch Schüler Conrings wurden in die Kontroverse hineingezogen: De controversiis Suecopolonicis sive de jure quod in Sueciam Regi ad Livoniam regno Poloniae competit / Hectore Ioannis Mithobii dissertatio (Helmestadii 1656). Die anonymen Flugschriften sind größtenteils in zwei Sammelbänden greifbar: Actorum \& gestorum; Fortsetzung: Actum \& gestorum (...) secundum, zusammen in Staats- und Universitätsbibliothek Göttingen $8^{\circ}$ H. Suec. 178/59; eine Wolfenbütteler Sammelschrift $8^{\circ}$ H. Suec. 178/53 enthält weitere 47 Drucke, wobei häufige Doppelungen auftreten. - Einige Textauszüge sind in: Die gelehrte Welt des 17. Jahrhunderts über Polen. Zeitgenössische Texte, hrsg. v. Elida M. Szarota (Wien 1972) 534-555 wieder abgedruckt. 69 Conring, De iustitia armorum, B1. A2v.

70 Ebenda, Bl. E3v: „Imo quod Gothi puondam effecerunt in ipsis illis Polonici hodie Regni provinciis. (...) Gothos simul trans Vistulam migraverunt (...) omnes populos inter mare Balthicum, Euxinum pontum \& Danubium suo imperio subjecisse." Conring, Epistola, Bl. F4r: „Und warumb sollten nicht heut zu Tage die Schweden und Gothen das praestiren und leisten / was vor Zeiten mit ihrem ewigen Lob die West- und Ost-Gothen in Italien / Spanien 
Aus diesen Schriften ergab sich ein Bild der polnischen Nation, das stark an deutsche humanistische Konstruktionen 150 Jahre zuvor erinnerte: Das Frankenreich habe sich bis zur Weichsel erstreckt ${ }^{71}$, Polen sei durch das ganze Hochmittelalter von Otto I. bis zu Friedrich II. vom Reich abhängig und dann Böhmen tributpflichtig gewesen ${ }^{72}$. Schlesien habe bereits seit dem 12. Jahrhundert nicht mehr zur Krone Polen gehört ${ }^{73}$. Weiterhin seien Preußen und der Deutsche Orden unter Kaiser Friedrich II. vom Reich abhängig geworden und nur durch spätere Vernachlässigung von seiten der Reichspolitik an Polen gefallen ${ }^{74}$. Schließlich habe die Einführung deutschen Rechts eine strukturelle Abhängigkeit des östlichen Europa vom Reich zur Folge gehabt ${ }^{75}$ - so Conring.

Inhaltlich wurden hier Geschichtsbild und Verfassung Polens als Fehlentwicklungen abgelehnt; neben aus der Sicht des Protestanten Conring verständlicher, scharfer Kritik an der Konfessionspolitik wurde erstmals der Vorwurf einer anarchischen Entwicklung in zentralen Verfassungsfragen laut, der die Nachbarn gefährde: Das polnische Staatswesen befinde sich in einem „höchstbetrübten und zerrütteten Zustande“ und wenn die Polen „nicht durch die Waffen den Schweden wieder unterwürffig gemacht werden, ihr gantzes Reich der Moscowiter, Cosakken, Tartarn und Türcken Wüterey wird zu Theil werden müssen"76, was die internationale Ordnung bedrohe. Dieser Argumentationsfigur sollte im 18. Jahrhundert noch eine große Zukunft beschieden sein.

Das umfangreiche Werk Conrings, durch das sich an zahlreichen Stellen zweifelnde und kritische Äußerungen zur polnischen Geschichte ziehen, wog schwer.

und an andern Orten / praestiret und verrichtet haben? Ja was die Gothen vor Zeiten in denen jetzigen Provincien des Königreichs Pohlen verrichtet haben. (...) dass die Gothen als sie uber die Weixel gangen (...) alle Völcker zwischen der Ost-See / dem Euxinischen Meer und der Donauw ihrem Regiment unterworffen."

71 Conring, De finibus Imperii Germanici 30-31; 820: „Vistula amne ad Balthicum mare a Caroli Magni aevo usque terminabatur Imperium Germanicum“.

72 „Ut proinde jure affirmaveris, Poloniam ab Ottonis Magni aevo usque ad Fridericum illum secundum, tantum non semper \& subjectam fuisse \& tributariam Imperio Germanico“, in: ebenda 338. Vgl. auch 324, 326, 336, 812. „Quondam habuit Regem, nunc autem DUCIBUS (divisa scilicet in partes) gubernatur. SERVIT \& ipsa, sicut Boemia, SUB TRIBUTO Imperatoriae Maiestati.“, in: ebenda 336 (Hervorhebungen im Org.).

73 Ebenda 812-817.

74 Conring, De finibus Imperii Germanici 820-840, hier 821: „At vero Friderici II Caesaris beneficio, non solum terrae Culmensis, sed totius Borussiae, omniumque terrarum (...) decretum \& confirmatum est.“

75 Conring, De origine iuris 191-193 enthält stärker abwägende Informationen über Polen: „diversa opinia est. Sunt enim qui autumant id accidisse, quo tempore regio illa tributum Germanico Imperio coepit pendere. Verum utut i eum modum Polonos olim subegerit Henricus Secundus, cum tributum illud annuum ad quingentas auri libras accessise ex Ottone Frigensi (...) videat posse colliginusquam tamen legas etiam jura iis praescripta. (...) Is imo est Casimirus qui Poloniam Germanico Imperio in totum subtraxit." In dem folgenden Beweis stützte sich Conring auf die Privilegierung deutscher Siedler und deutschen Rechts sowie die Einbeziehung Schlesiens in die Reichsstrukturen und leitete daraus eine polnische Abhängigkeit ab.

76 Conring, Epistola, B1. D1v-D2r. 
Als einer der Begründer einer deutschen Rechtsgeschichte und historischen Reichsverfassungslehre besaß Conring auf die gesamte Reichsgeschichtsschreibung der frühen Neuzeit prägenden Einfluß. Durch einen breiten Schüler- und Bewundererkreis, die in ihm ein „seculi miraculum “ sahen, intensiv rezipiert ${ }^{77}$ und durch die Folioausgabe von 1730 bequem zugänglich ${ }^{78}$, behielten Conrings Positionen zu Polen bis weit ins 18. Jahrhundert ihre Ausstrahlungskraft. In der deutschen Rechtsgeschichte und Reichspublizistik erwuchs daraus ein kritischpolemischer Blick auf die polnische Geschichte, die in starker Abhängigkeit von der Reichsgeschichte gesehen wurde. Über die entstehende deutsche und europäische bürgerliche Öffentlichkeit drangen solche Positionen auch in ein breiteres Publikum vor.

Unter Conrings Einfluß entstand in den 1670er Jahre eine preußische Geschichtsparabel, die nun Preußen in Germanien verortete. Der spätere Königsberger Ratsherr und Bürgermeister Michael Kongehl (1646-1710), der Rechtswissenschaften studiert hatte, veröffentlichte 1676 seinen historischen Roman „Surbosia“, in dem über die Entführung der Prinzessin Surbosia - ein Anagramm für Borussia - berichtet wird. In der Handlung ist Surbosia eine Tochter von Prussarchus, des Königs der germanischen Hulmigeria ${ }^{79}$, deren Hand trotz des Wider-

77 Zum Beispiel Philipp Andreas Oldenburger, Thesaurus rerum publicarum. Pars 1-4. Genevae 1675. Dort findet sich in Bd. 2 51-184 ein Abdruck des „Textus Conringii De Republica Polonorum“. in einer gegenüber den Gesammelten Werken abweichenden (nicht von dessen Herausgeber Johann Wilhelm Goebel überarbeiteten) und gegenüber Polen erheblich kritischeren Fassung. Einige Auszüge: 51 (Polens Geschichtsschreiber verdienten keinen Glauben; die Nation komme bei antiken Autoren nicht vor, werde erst von deutschen Geschichtsschreibern erwähnt und sei folglich zur Germania zu zählen): „Nulla vero in antiquis monumentis Polonorum fit mentio (...) Post hunc apud nullum scriptorem reperias vocem Polonorum; altum enim silentium sque ad Sec. IX, quo a Scriptoribus rerum Germanicarm res illorum memorari caeperunt, quia partem Germaniae constituerunt.“ Deshalb: „Poloniae quondam Germaniae subiecta." 52: vor Długosz gebe es keine polnische Geschichtsschreibung: „nil habent antiquitatis natum ante Martinum Buglossium [= Jan Długosz, H.-J. B.], cuius opus tamen nunquam prodiit in lucem, nec enim permittunt illi prodire, sed supprimunt, forsan quia multa narrat, quae non placet, nec ad palatum sunt." 54: Schlesien habe eigentlich niemals zu Polen gehört: „proprie ad Poloniam nihil pertinuit, nisi quod Poloniae majoris \& minoris nomine comprehenditur, deinde \& Silesiae." Der Conringsche Vorlesungstext zirkulierte unter deutschen Rechtshistorikern und wurde auch von anderen Autoren benutzt, vgl. Goldschlag, Beiträge 69-72 mit Hinweis auf weitere Abhängigkeiten.

78 Hermann Conring, Hermani Conringii Operum (...), 7 Bde. (Brunsvigae 1730) Bd. 4, Varia scripta 47-548: „Examen Rerum publicarum totius orbis“, dort 416-432: „De Polonia Republica“. Vgl. auch die zentrale Schrift für Conrings Staatenkunde: Exercitatio HistoricoPolitica de Notitia singularis alicujus Reipublicae, in: Conring, Opera Bd. 7, wo an der These, daß „Optimates (...) potissimum scopum esse luxuriosam vitam“ als Zweck der polnischen Verfassung gelten könne, festgehalten wird.

79 Andreas Keller, Die Preußische Nation und ihre literarische Genese: Grundzüge eines regionalen Geschichtsbewußtseins und die intentionale Vermittlung einer territorialen Identität in Michael Kongehls Roman Surbosia (1676), in: Kulturgeschichte Ostpreußens in der Frühen Neuzeit, hrsg. v. Klaus Garber u. a., Frühe Neuzeit 56 (Tübingen 2001) 737-767 hier 755-756 liest „Hulmigeria“ als Samland. Es handelt sich jedoch um einen Bezug auf Piccolominis und Stellas altes Preußen ohne kleinregionale Konkretisierung. Zu Kongehls Werk: 
stands der Prinzessin von dem negativ konnotierten Prinzen Lettus (=Lech) von Sarmatien gefordert wird. Als Retter tritt Irenando, der Sohn des Königs von Marginea (= Germania) auf. In diese leicht entschlüsselbare Handlung wird zudem noch die Bedrohung des Reichs durch die Invasion Ludwigs XIV. in „Germanien“ integriert. Am Ende bricht die Erzählung mit der Flucht des Prinzen Lettus $a b^{80}$.

Preußen wird hier - im Gegensatz zu den zeitgenössischen Positionen unter den ständischen Eliten der Region - als Teil eines deutschen Reichszusammenhangs in Anspruch genommen. Dabei handelte es sich allerdings im letzten Drittel des 17. Jahrhunderts um eine Minderheitenposition, die den Einflüssen der Conringschen Rechtsgeschichte geschuldet war und auf ältere preußische humanistische Traditionen (Erasmus Stella) zurückgriff.

Unter preußischen und polnischen Hörern Conrings lösten dessen Auffassungen jedoch mehrheitlich Kritik aus. Johannes Sachs (1641-1671), der aus dem großpolnischen Fraustadt stammte und als Schreiber in Thorn tätig war, veröffentlichte nach dem Studium bei Conring 1665 eine Polemik, in der er diesem Fehleinschätzungen vorwarf ${ }^{81}$. Der preußische Historiker Christoph Hartknoch (1644-1687) setzte sich mit Conrings Positionen auseinander und wies auf die zeitgenössischen politischen Hintergründe hin ${ }^{82}$.

Andreas Keller, Michael Kongehl (1646-1710). Durchwandert ihn / gewiß! Ihr werdet anders werden (...). Transitorische Textkonstitution und persuasive Adressatenlenkung auf der Basis rhetorischer Geneseprinzipien im Gesamtwerk des Pegnitzschäfers in Preußen (Berlin 2004).

80 [Michael Kongehl], Surbosia / Das ist Geschichtmässiges Helden-Gedicht / Darinn unter allerhand Gemühts-Belustigungen / auch einige Krieges-Händel / Die sich seither in Oberund Nieder-Deutschland zugetragen / enthalten und verblühmter Weise / erzehlet werden. Von einem Mitglied der Löblichen Blumen-Gesellschafft (Nürnberg 1676).

81 [Johannes Sachs], Francisci Marinii De scopo Reipublicae Polonicae, adversus Hermannum Conringium, professorem Helmstadiensem, dissertatio qua simul Status Regni Poloniae novissime describitur (Vratislaviae 1665); deutsche, von der Stadt Danzig in Auftrag gegebene Ausgabe: [Johannes Sachs], Francisci Marinii Eines Pohlnischen Patrioten Staat des Königreichs Pohlen / worinnen sowohl Die wahre Forme und Gestalt der Pohlnischen Republic und Königreichs, als auch die vormahlige und heutige Gewalt der Könige (...) deutlich gezeiget, und letztlich gewiesen wird, daß dasjenige, was der vormahlige hochberühmte Helmstädtische Professor, Herr Hermann Conring, von dem Endzwecke der Pohln. Republic heraus gegeben unrichtig und falsch sey (...) (Dantzig 1726); zu Sachs: Polski Słownik Biograficzny [Polnisches biographisches Lexikon, im folgenden PSB], Bd. 34 270; Entgegnung von Johannes Mothius, einem Schüler Conrings: De scopo Reipublicae Polonicae et domo Austriaca adversus Franciscum Marinium Polonum libellus quo vir summus Hermanus Conringius ab ineptiis et calumniis quas dissertatio Marinii de scopo Reipublicae Polonicae parturit, vindicatur (Hamburgi 1665). Zu dem Archivar Moth (1639-1705) vgl. Dansk Biografisk Leksikon, Bd. 1079.

82 Christoph Hartknoch, Respublica polonica duobus libris illustrata; quorum prior, Historiae Polonicae memorabilia, ex diligenti Sarmaticorum pariter atque Germanicorum tam Veterum, quam recentiorum Scriptorum collatione (...) Posterior vero, Jus publicum Reipublicae Polonicae, Lithuanicae (...) comprehendit. (...) (Francofurti et Lipsiae 1678); zweite Auflage unter dem Titel: Christoph Hartknoch, De Republica Polonica libri duo quorum prior Historiae Polonicae memorabiliora ex diligenti Sarmaticorum juxta ac Germanicorum tam 
Unter den patrizischen Eliten Danzigs wurde die Auseinandersetzung mit den Thesen Conrings als so bedeutend erachtet, daß eine grundsätzliche Widerlegung in Auftrag gegeben wurde. 1694 gab der dortige Rechtshistoriker Johannes Schultz ${ }^{83}$ seine Schrift "Tractatus historico-politicus de Polonia nunquam tributaria" heraus, die die humanistische Konstruktion einer unabhängigen polnischen Nationalgeschichte neu akzentuierte ${ }^{84}$. Vorausgegangen waren zwischen 1689 und dem Mai 1694 zehn Disputationen mit Schülern der höheren Klassen des Akademischen Gymnasiums, die ebenfalls gedruckt wurden ${ }^{85}$. Die zentrale These war die Zurückweisung jeglicher Abhängigkeit. Die polnische Nation und ihr Staat seien niemals tributpflichtig gewesen ${ }^{86}$. Dabei wurden auch Preußen, Litauen und Livland als Teil der "Sarmatia“ angesehen ${ }^{87}$. Als Resultat erschien so das Bild eines autochthon-eigenständigen nationalen Werdegangs.

Schultz, der auch als Autor von an Jan Sobieski addressierten Gelegenheitsschriften hervortrat ${ }^{88}$, wurde mit Urkunde vom 7. März 1695 geadelt und als königlicher Geschichtsschreiber ausgezeichnet ${ }^{89}$. Seine Darstellung von 1694 endete

Veterum, quam recentiorum Scriptorum collatione eruta, variasque Provinciarum eo pertinentium mutationes complectitur: Posterior autem Jus Publicum Reopubl. Polonicae, Lithuanicae (...). His adjectae sunt Duae Dissertationes Historiace De Republica Curonica (...) De originibus Pomeranicis (...) (Francofurti, Lipsiae 1687); 31698 ; Analyse von Conrings Positionen in allen Ausgaben: (1678) 30-39; (21687) 45-59; (31698) 42-55.

83 Zu Schultz vgl. PSB, Bd. 36 29-31; Henryk Grajewski, Jan Schultz Szulecki i jego Tractatus historico-politicus de Polonia nunquam tributaria (1694 r.). Studium z dziejów polskiej literatury prawniczej [Johann Schultz-Szulecki und sein Tractatus historico-politicus de Polonia nunquam tributaria (1694). Eine Studie zur Geschichte der polnischen Rechtsliteratur] (Łódź 1964); Lech Mokrzecki, Jan Schultz-Szulecki (1662-1704) prawnik i historyk pomorski [Johann Schultz-Szulecki (1662-1704), ein Jurist und pommerellischer Historiker], in: Zapiski Historyczne 38 (1973) 9-30. Trotz dieser Arbeiten ist eine Gesamteinschätzung des Werks von Schultz-Szulecki ein Desiderat, da dessen Tätigkeit in Frankfurt a.d. Oder (1682-1688 und 1698-1704) nicht aufgearbeitet ist und eine Gesamtbewertung fehlt.

84 Jobannes Schultz, Tractatus historico-politicus de Polonia nunquam tributaria (...) (Gedani 1694) 57: „nulla Romano-Germanico Imperio, iure successionis forte, in nostram Gentem potestas, vel potestatis imago“.

85 Johannes Schultz, Disputationes Iuris Publici De Polonia nunquam tributaria (...) Praeside Dn. Johanne Schultzio (...) Fautore et Praeceptore (...). Sectio I-X (Gedani 1694). Die Disputanten stammten mehrheitlich aus dem Danziger Patriziat: Johannes Daniel Schlieff, Albertus Rosenberg, Benjamin Ewald, Joachimus Henricus Schrader, Daniel Schrader, Salomon Hahn (Marienburg), Christian Daberhudt, Georgius Kesselhut, Henricus Freder, Hieronymus Proen.

86 Schultz, Disputationis, Sectio II, 1: „Polonia nunquam subiecta aut tributaria facta rationibus a nominum impositione, indole, moribus, ortu, linguae et vestium exterarum usu, etc. etc. petitis exhibetur".

87 Schultz, Tractatus 301-302.

88 Serenissimo atque Potentissimo Principi ac Domino, Domino Joanni III Poloniarum Regi, Pio, Felici, Augusto, Libertatis non Sarmaticae tantum, sed \& Europaeae Vindici ac Statori invictissimo (...) ac memoria pacis Oliviensis (...) panegyris habita a Joanne Schultzio Prusso-Polono (Gedani 1694) [unpaginiert], dort Wiederholung der zentralen These: „Poloniam, ergo, nunquam Tributarium, tanquam debitum Heroibus Praedecessoribus Gratiae Decus, a calamo obligationis haud immemore repensum Orbi exhubui literario."

89 Gerard Labuda, O nobilitacji Jana Schultza-Szuleckiego, historiografa króla Jana Sobies- 
mit dem Sieg Johann Sobieskis bei Wien, der die Gelegenheit bot, die Verteidigung nationaler Unabhängigkeit und europäischer Freiheit besonders zu akzentuieren sowie die polnischen Verdienste herauszustellen ${ }^{90}$. Hier ist spiegelbildlich gegenüber Conring der politische Auftragscharakter der jeweiligen gelehrten Arbeiten erkennbar.

Selbst mit diesen Widerlegungen war das Thema für die protestantische preuBisch-polnische Historiographie nicht erledigt: Noch die Erstausgabe von Johannes Długoszs Geschichtswerk (1711/12) zitierte Conrings Meinung über die polnischen Geschichtsschreiber und wollte dieses Urteil - u. a. mit einer von Danziger Seite erarbeiteten Bibliographie von Joachim Hoppe - korrigieren ${ }^{91}$. Samuel Friedrich Lauterbach (1662-1728) formulierte 1727 drastisch „Conring verachtet die Polnischen Historicos" und wies darauf hin, daß Parteilichkeit auf beiden Seiten $\mathrm{zu}$ finden sei92. Bemerkenswert ist, daß sich die zentralpolnischen Eliten an diesen Debatten nicht beteiligten und sie möglicherweise nicht zur Kenntnis nahmen. Diskutiert werden kann, ob hier eine Arbeitsteilung vorlag oder die polnischen Eliten infolge der nach 1648 wachsenden Abschottung von der europäischen Ideengeschichte die weitreichende Wirkung Conrings und dessen rechtshistorischen Schule in Mitteleuropa nicht erkannten.

In mancher Hinsicht besitzt die Kontroverse Conrings mit der gelehrten preuBisch-polnischen Geschichtsschreibung in der zweiten Hälfte des 17. und den ersten Jahrzehnten des 18. Jahrhunderts ein Janusgesicht: Sie knüpfte an Auseinan-

kiego w roku 1695 [Die Nobilitierung Johann Schultz-Szuleckis, des Historiographen Jan Sobieskis, 1695], in: Rocznik Gdański 33 (1973) 111-116, mit Abdruck einer Abschrift der Urkunde. Dort heißt es ,generosus Joannes a Scholtz, rerum nostrarum, si nondum scriptor, indubie tamen ex editis jam in lucem literariis de regno Poloniae documentis, historiographus futurus".

90 Schultz, Disputationis 338: „HEROS JOHANNES TERTIUS, non Polonae tantum sed \& Europae omnino Libertatis Vindex \& Stator“.

91 Ioannis Długossi seu Longini canonici quondam cracoviensis Historiae Polonicae libri XII. Quorum sex posteriores nondum editi, nunc simul cum prioribus ex Mscripto rarissimo in lucem prodeunt (...) Samuelis Ioachimi Hoppii, schediasma de scriptoribus historiae Polonicae plurimus annotationibus auctum Gabrielis Groddeckii (...), 2 Bde. (Lipsiae 17111712) Bd. 1, Praefatio ad lectorem. Das ganze Vorwort ist in vieler Hinsicht gegen Conring aufgebaut, u. a. heißt es: „Neque dissimulare possum, scriptores Germanicos ipsos frequentissime inter se in percensendis gentium suarum rebus dissentire (...). I nunc \& Germanorum fidem extolle, atque monumenta eorum Annalibus Polonorum antepone. Quos ego si non amore, certe aequali loco cum Germanis habendos \& utrosque ad eruendam veritatem simul simul conferendos esse intrepidus affirmo."

92 Samuel Friedrich Lauterbach, Pohlnische Chronicke, oder, Historische Nachricht von dem Leben und Thaten aller Hertzoge und Könige in Pohlen, von Lecho an bis auf (...) Augustum II. Nebst ihren eigentlichen Bildnüssen, aus sehr vielen fleißig nachgeschlagenen Geschicht-Büchern bey einer noch nicht habenden angenehmen Ordnung, und in Acht unterschiedene Alter eingetheilet (...) (Franckfurth, Leipzig 1727) Bl. B3: „Der berühmte Hermannus Conring selbst hält diese Nation so gering, dass er auch alle Historicos verwirfft, als denen gar nicht zu trauen, was sie geschrieben, und sollte man lieber die Polnische Historie aus den Teutschen Schrifften bauen, die viel gewissenhafter wären (...). Da doch, wenn mans beym Lichte besiehet, eben das, was hie an den Polnischen Scribenten getadelt wird, bey den Teutschen und andern eben so wohl zu finden." 
dersetzungen zwischen deutschen Humanisten und ihren polnischen Kontrahenten 150 Jahre zuvor an. Zugleich nahm die Kontroverse die deutsch-polnischen Auseinandersetzungen des späten 18. und 19. Jahrhunderts vorweg, in denen der Vorwurf eines anarchischen Staatsaufbaus akzentuiert wurde, der in die Kritik an der „polnischen Unordnung“ und in die Begriffsprägung der „polnischen Wirtschaft" mündete.

Ein Unterschied ist allerdings nicht zu übersehen: In den Kontroversen des späten 17. Jahrhunderts standen auf beiden Seiten Protagonisten, die nicht durch ethnisch-sprachliche Determinanten beeinflußt wurden. Der Fraustädter Sachs oder der aus Graudenz stammende Schultz waren protestantische und deutschsprachige Untertanen des polnischen Königs, Hartknoch stammte aus dem östlichen Preußen. Ihre Herkunft und ethnische Zugehörigkeit hatten auf ihre Argumentation keinen Einfluß. Eine Polarisierung entlang einer ethnisch-sprachlichen Grenze fand noch nicht statt.

Das humanistische Konstrukt „deutsche Nation“ und die schrittweise Entwicklung einer deutschen nationalen Öffentlichkeit (humanistische Zirkel, Reichspublizistik) führte zu einem tief verankerten frühneuzeitlichen polnischdeutschen Disput über die geographische Reichweite der jeweiligen Nationalgeschichte (Elbe-, Oder- oder Weichselgrenze) und ihre Abhängigkeit bzw. Unabhängigkeit voneinander. Vergleichbar sind diese Dispute mit denjenigen italienischer und deutscher Humanisten. Bemerkenswert ist die konfligierende Rhetorik auch deshalb, weil sie sich frühneuzeitlich kaum auf aktuelle Konflikte stützen konnten, sondern in erster Linie auf sich in der politischen Kommunikation durchsetzenden Denkmustern basierten. Diese Dispute verstellten eine Wahrnehmung der strukturellen verfassungsrechtlichen Ähnlichkeit zwischen Altem Reich und Polen-Litauen wie auch Einsichten in die Reproduktion ähnlicher $\mathrm{Mu}-$ ster (kriegerische Tugenden, ewige Unbesiegtheit) in beiden Nationskonstrukten.

Unter den deutschsprachigen Bevölkerungen jenseits der Reichsgrenze, im Preußenland, in Livland oder in Krakau, fand die Vorstellung von einer „deutschen Nation" frühneuzeitlich nur geringe Anziehungskraft. Dies änderte sich erst allmählich im späten 17. Jahrhundert, als sich eine Ausstrahlung der historische Rechtsschule Hermann Conrings in das Herzogtum Preußen belegen läßt. Im 18. Jahrhundert trat eine wachsende Nationalisierung der lutherischen deutschsprachigen Bevölkerung im Königlichen Preußen hinzu, die sich nach Versuchen einer konfessionellen katholischen Homogenisierung allmählich als eine protestantische deutsche Minderheit konstituierte ${ }^{93}$. Bedeutung besaß hier die zu einem europäischen Medienereignis gewordene Bestrafung der Thorner protestantischen Eliten 1724/25 mit der Hinrichtung des Bürgermeisters Johann Gottfried Rösners (1658-1724) an der Spitze. Allerdings hielten die die städtische Politik bis 1772/93 kontrollierenden Patrizierfamilien auch noch im 18. Jahrhun-

93 Michael G. Müller, Städtische Gesellschaft und territoriale Identität im Königlichen Preußen um 1600. Zur Frage der Entstehung deutscher Minderheiten in Ostmitteleuropa, in: Nordost-Archiv 6 (1997) 565-584. 
dert aus politischen wie wirtschaftlichen Interessen an einer vermittelnden Position eines als Teil des polnisch-litauischen Reichsverbandes definierten altständischen preußischen Nation fest ${ }^{94}$.

Das Ordnungsmodell „deutsche Nation“ bewies insgesamt eine erhebliche Ausstrahlung im östlichen Europa. Es stieß eine konkurrierende polnische Nationsbildung erheblich an, die sich antagonistisch zu deutschen Identitätsentwürfen positionierte, die einen autogenen deutschen Geschichtsraum (Germania Magna, Vandalia) in ganz Ostmitteleuropa beanspruchten und der polnischen Staatlichkeit lediglich eine Nachrangigkeit zuwiesen (Conring). In der - zu einem erheblichen Teil lediglich imaginierten - militärischen und politischen Abwehr solcher Bestrebungen entwickelte die Ehrgemeinschaft des polnischen Adels ein herausgehobenes Verständnis einer ewig unbesiegten Gemeinschaft (Polonia numquam tributaria).

Von polnischer Seite wurde in diesen Kontroversen die deutsche Nation nicht als libertäres, sondern als bürokratisches und tendenziell „tyrannisches“ Ordnungsmodell beschrieben. Als Folie dienten hierzu die bürokratisch-zentralisierenden Bestrebungen der habsburgischen Herrscher bei den ostmitteleuropäischen Nachbarn Böhmen und Ungarn, die keinesfalls als „Erblande“ wahrgenommen wurden, sowie das entwickelte höfische Zeremoniell auch an den kleineren Höfen des Reichs. Auch die Reichsverfassung erschien aus dieser Perspektive als stark aristokratisch und wenig partizipatorisch geprägt. Diese Wahrnehmung verschleierte - mit bis in die populäre wie fachwissenschaftliche Geschichtskultur der Gegenwart nachwirkenden Folgen - den Blick für die tatsächlichen Ähnlichkeiten in beiden Reichsverfassungen.

\section{Summary}

The article deals with the development of German and Polish national and historical discourses, their interaction and their reaction to each other from the early $16^{\text {th }}$ century to the late $17^{\text {th }}$ century. These include the humanistic discourses (15001550), the public media of the Interregna period $(1572,1575,1586 / 1587)$, the denominational disputes (1587-1668) and the debates between German and Polish historians of law (late 17th century). Polish humanistic national models were developed in reaction to earlier German ideas, particularly in two contexts: on the one hand in the bourgeois and academic environment of Cracow and on the other hand in the diplomatic and military relations between the Teutonic Order and Poland. In response to the German notions (Celtis, Hessus, Agricola, Aventinus) of an ancient German heritage (Germania Magna) and the idea of the original dependence of Poland on the Reich, the Polish elites (von Miechow, Bielski, Kromer) created a narrative of history (Sarmatia magna) that both rejected Bohe-

94 Karin Friedrich, The Other Prussia. Royal Prussia, Poland and Liberty, 1569-1772 (Cambridge 2000). 
mian influences and any tributary relations to the Kaiser and minimized the importance of the Jagiellon dynasty. It is important to notice that this discourse was not founded on ethnicity or language, but on loyalty to the Polish crown. The German citizens of Cracow were, for example, scarcely affected by these ideas. In the time of the Interregna these national concepts were instrumentalised in election propaganda and were widely diffused by means of the intensive use of public media among the nobility of the whole Commonwealth. The debate about the Polish polity was conducted in terms of the juxtaposition of the idea of "German tyranny" to that of "Polish freedom". The denominational dispute was linked with the unpopularity of the Wasa court, which was dominated by the German language. Bishops Pawel Piasecki even denounced Protestantism as a „German heresy" and some also the antipathetic image of tyranny was also extended to the Swedish crown and to the Catholic Habsburgs. For their part the German Protestants (Thomas Lansius) contributed the "descriptio gentium": literature which emphasized the weakness of the Polish kings. This marked the origin of the textual tradition that defended Poland, to which Poles as well as Germans (e.g. Gadebusch) contributed. As one of the founders of the history of German law Hermann Conring had substantial influence on the image of Poland in Germany and Europe in the seventeenth and eighteenth-centuries, particularly since he ignored the medieval independence of Poland and introduced the reproach that central constitutional principles in Poland had developed anarchically. The opposition to these ideas on the part of the Prussian elites (Sachs, Hartknoch), especially in Danzig (Schultz), was remarkable, whereas the nobility of central Poland remained largely indifferent to them. Finally it is significant that these concepts were neither generated by actual conflicts nor dominated by ethnic categories as they later came to be in the eighteenth and nineteenth centuries. They were, however, related to new emerging modes of political thinking. Interestingly, these also painted over the structural constitutional similarities between the Old Reich and PolandLithuania. 
